\title{
Arcabouço geofísico-estrutural da porção meridional do Cinturão Ribeira
}

\author{
Geophysical-structural framewok of southern Ribeira Belt
}

\author{
Luís Gustavo de Castro ${ }^{1 *}$, Francisco José Fonseca Ferreira ${ }^{1}$
}

\begin{abstract}
RESUMO: Os diversos estudos apresentados para explicar a configuraçáo atual e a evolução da porção meridional do Cinturão Ribeira refletem a complexidade dos processos envolvidos na formaçáo desses terrenos. Com base na análise qualitativa (realce de anomalias) e semiquantitativa (estimativas de profundidades de fontes) de dados aeromagnéticos e modelagem gravimétrica, o presente trabalho apresenta modelos geofísico-geológico-estruturais dessa região. A integração de resultados qualitativos e semiquantitativos, balizada pela geologia da área, constituiu a base para elaboração dos modelos. A aplicação de métodos de realce de anomalias (análise qualitativa) mostrou a continuidade de lineamentos correspondentes à Zona de Falha de Taxaquara e às zonas de cisalhamento Itapirapuá, Morro Agudo e Lancinha sob a Bacia do Paraná. Tal interpretaçẫo foi validada pelas soluçôes de Euler, que mostram profundidades superiores a $2.000 \mathrm{~m}$, relacionadas a essas estruturas, tanto no embasamento como em seus prolongamentos sob a Bacia do Paraná. Os modelos gravimétricos, elaborados em níveis de profundidade distintos, indicaram um afinamento crustal de NW para SE, com porçôes de espessura crustal diferenciadas limitadas pelas zonas de cisalhamento.
\end{abstract}

PALAVRAS-CHAVE: Aeromagnetometria; Modelos gravimétricos; Zonas de cisalhamento.

\begin{abstract}
The diversity of works and models presented to explain the evolution and current setting of southern portion of the Ribeira Belt reflects the complexity of the processes involved in such terrains. Based on qualitative (anomalies enhancement) and semi-quantitative (source depths detection) analysis of aeromagnetic data and gravity data modeling, this work presents geophysical-geological-structural models of this region. The integration of qualitative and semi-quantitative analysis, constrained by the geological data, formed the basis for the elaboration of models. The application of methods of anomalies enhancement (qualitative analysis) showed that the lineaments of Taxaquara Fault Zone and Itapirapuã, Morro Agudo and Lancinha shear zones spread under the Paraná Basin. This interpretation was validated by Euler solutions, which located sources with depth greater than 2,000 m, related to these structures. The gravity models, which were elaborated in distinct depth levels, indicate a crustal thinning from $N W$ to $S E$, with different crustal thickness portions bounded by the shear zones.
\end{abstract}

KEYWORDS: Aeromagnetometry; Gravity models; Shear zones

${ }^{1}$ Laboratório de Pesquisas em Geofísica Aplicada, Centro Politécnico, Departamento de Geologia, Universidade Federal do Paraná - UFPR, Curitiba (PR), Brasil. E-mail: lgcastro7@gmail.com; francisco.ferreira@ufpr.br

*Autor correspondente.

Manuscrito ID: 20150007. Recebido em: 12/06/2015. Aprovado em: 06/10/2015. 


\section{INTRODUCÃO}

A distribuição espacial das unidades, assim como sua associação com as zonas de cisalhamento da porção meridional do Cinturão Ribeira, constitui um desafio já discutido em diversos trabalhos (Fiori 1992; Basei et al. 1992, 1998, 2008; Campanha 2002, Heilbron et al. 2008). Contudo, poucos são os que se utilizam da modelagem de dados de campos potenciais (e.g. gravimetria e magnetometria) como ferramenta para esse propósito (Rosales 2004, Ferreira et al. 1988).

O presente estudo se propóe a verificar a distribuição espacial das zonas de cisalhamento neoproterozoicas na porção meridional do Cinturão Ribeira, assim como sua continuidade sob a Bacia do Paraná, com base no processamento, na interpretação e na modelagem de dados aeromagnéticos e gravimétricos terrestres.

A análise resultou da integração de mapas de realce de anomalias (análise qualitativa), estimativas de profundidades de fontes e análise espectral (análise semiquantitativa) dos dados aeromagnéticos com mapas geológicos. Os resultados apoiaram a construção de modelos geológico-geofísico-estruturais (análise quantitativa) elaborados com base em dados gravimétricos terrestres de três transectas regionais segundo NW-SE, perpendiculares ao trend estrutural regional.

A área estudada contempla a porção meridional do Cinturão Ribeira, centro-sul da Província Mantiqueira, além de áreas na Bacia do Paraná (Fig. 1). Abrange as porçôes sudeste do Estado de Sáo Paulo, leste do Estado do Paraná e nordeste do Estado de Santa Catarina (Fig. 1).

O Cinturão Ribeira (CR), ou Faixa Ribeira (Almeida et al. 1973), na porção central da Província Mantiqueira (Almeida et al. 1981), é caracterizado por uma faixa de dobramentos e empurrôes de direção NE-SW, com cerca de $1.400 \mathrm{~km}$ de comprimento, localizado ao longo do Sudeste do Brasil (Heilbron et al. 2000, Heilbron et al. 2004, Peternel et al. 2005).

Heilbron et al. (2008) sintetizam o Cinturão Ribeira como um conjunto de terrenos tectono-estratigráficos limitados por falhas de cavalgamento ou por zonas de cisalhamento transpressivas. Sua porção meridional é caracterizada por domínios NE-SW, compostos predominantemente por rochas supracrustais meso a neoproterozoicas (Campanha 2002, Basei et al. 2008).

De NW para SE afloram os Terrenos Apiaí, Curitiba, Luis Alves e Paranaguá (Fig. 2), os quais foram individualizados

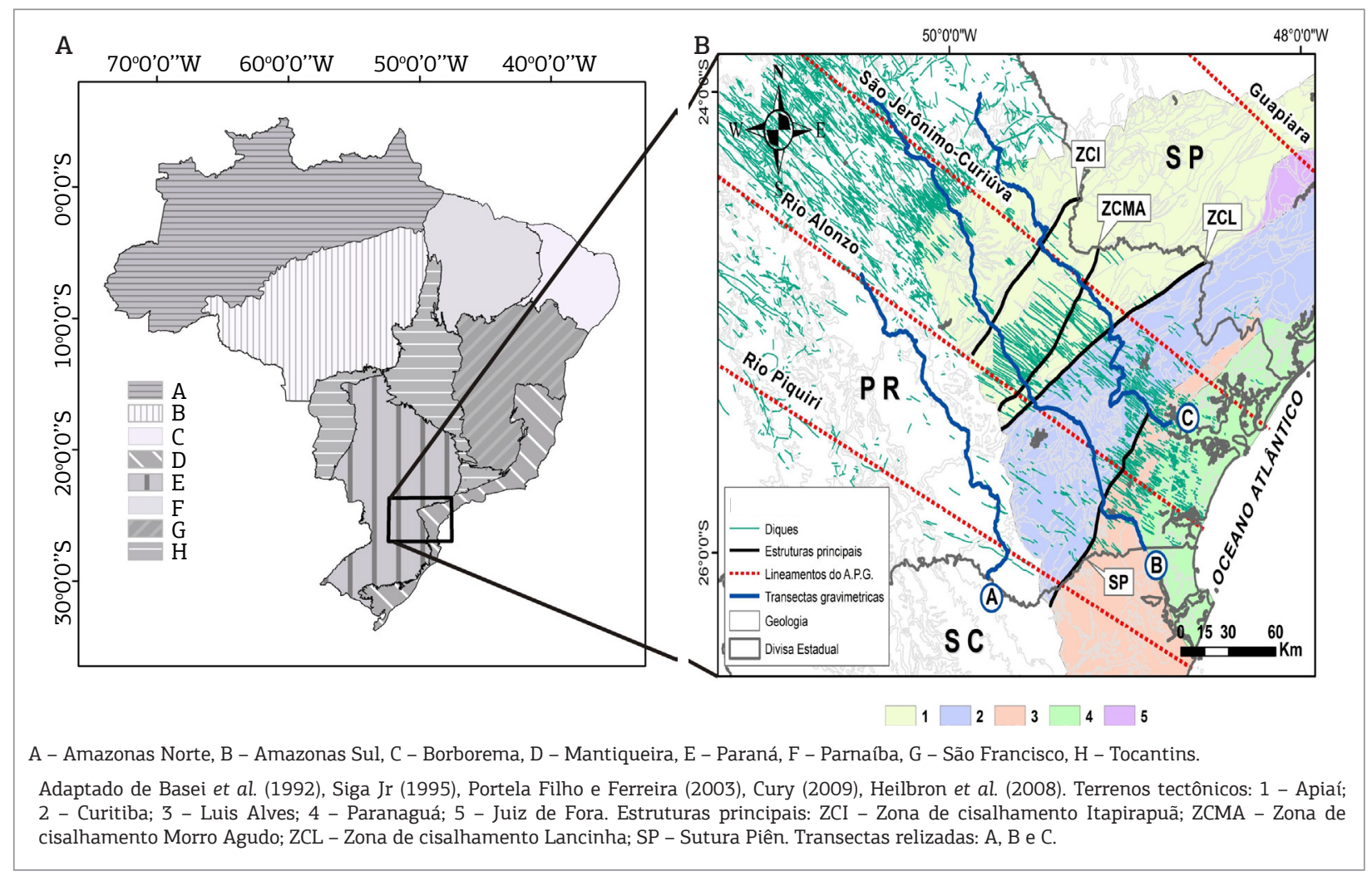

Figura 1. (A) Províncias Estruturais do Brasil indicando a área de estudo (polígono preto), modificado de Almeida et al. (1981) e Bizzi et al. (2001). (B) Compartimentação tectono-estrutural da área de estudo e alinhamentos do Arco de Ponta Grossa. 
com base em estudos geológicos envolvendo características litológicas, petrográficas, estruturais, geocronológicas e geoquímicas, além de dados gravimétricos (Basei et al. 1992, Cury 2009).

O Terreno Apiaí é constituído por sequências metavulcanossedimentares meso e neoproterozoicas, núcleos do embasamento paleoproterozoico e maciços graníticos neoproterozoicos, cuja associação compóe compartimentos tectônicos balizados por expressivas zonas de cisalhamento num contexto deformacional transpressivo (Fiori 1990, 1992, Campanha \& Sadowski 1999, Cury 2009, Heilbron et al. 2008, Siga Jr. 2010).

O Terreno Curitiba é composto por gnaisses-migmatíticos do Complexo Atuba gerados no Paleoproterozoico (c.a. 2.0 Ga), sobrepostos por uma sucessão metassedimentar de margem passiva representada pelos metassedimentos das sequências Capiru, Setuva e Turvo-Cajati, afetadas por um episódio metamórfico a $600 \mathrm{Ma}$ (Heilbron et al. 2008, Cury 2009).

Seu limite com o Terreno Apiaí a noroeste é definido pela Zona de Cisalhamento Lancinha (ZCL), interpretada por alguns autores como uma sutura entre as duas unidades (Basei et al. 1998). O limite com o Terreno Luis Alves a sudeste é dado pela Zona de Cisalhamento Piên (ZCP) (Siga Jr. et al. 1995), cuja associação com rochas relacionadas a arco constitui para alguns autores uma evidência de subducção (Heilbron et al. 2008).

O Terreno Luis Alves é constituído por gnaisses granulíticos, metamorfisados em médio a alto grau (Basei et al. 1992, 1998). Ocorrem subordinadamente rochas migmatíticas e graníticas, básicas e ultrabásicas, além de gnaisses calciossilicáticos, kinzigitos, formações ferríferas e quartzitos (Cury 2009).

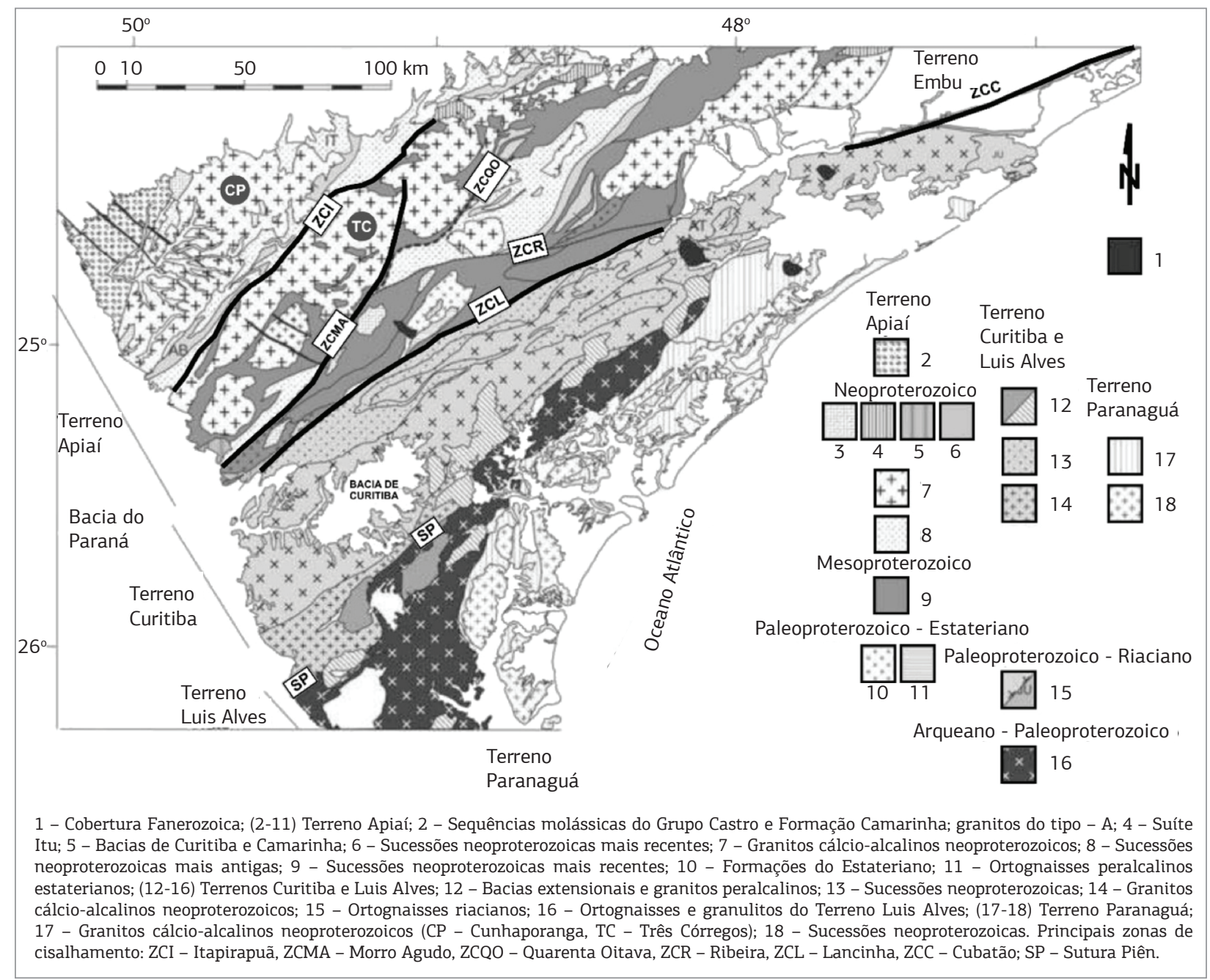

Figura 2. Mapa geológico da porção meridional da Faixa Ribeira (modificado de Heilbron et al. 2008). 
OTerreno Paranaguá é constituído predominantemente por um complexo ígneo, composto de uma grande variedade de rochas graníticas, cujas encaixantes são gnaisses, xistos, quartzitos, mármores, rochas calciossilicáticas e anfibolitos (Cury 2009).

O contato com os terrenos Luis Alves e Curitiba é representado em sua porção sudoeste pelo lineamento do Rio Palmital, na porção oeste-noroeste pelos lineamentos Alexandra e Serra Negra, além das zonas de cavalgamento Serra Negra e Icapara em sua porçáo setentrional.

Com exceção do Terreno Paranaguá, os terrenos mencionados compóem o embasamento da Bacia do Paraná. A bacia, tipicamente intracratônica (Almeida et al. 1981, Milani e Ramos 1998), abrange uma área de aproximadamente $1.750 .000 \mathrm{~km}^{2}$ (Almeida et al. 1981), ocupando a região Sul e porçóes das regiôes Sudeste e Centro-Oeste do Brasil, além de parte do Paraguai, Argentina e Uruguai.

Seu preenchimento atinge a espessura máxima $7.000 \mathrm{~m}$ (Milani et al. 2007), sendo predominantemente siliciclástico, com carbonatos e rochas ígneas subordinadas. Comporta o registro estratigráfico entre o Ordoviciano e o Cretáceo (Zalán et al. 1987, Oliveira 1991, Milani e Ramos 1998).

A influência das estruturas do embasamento na instalação e evolução da bacia é consensual e foi discutida por diversos autores (Almeida et al. 1981, Ferreira 1982a, Soares et al. 1982; Cordani et al. 1984; Brito Neves et al. 1984, Milani 1997, Milani e Ramos 1998, Zalán et al. 1987, Quintas 1995), permanecendo controvérsias com relação a sua distribuição espacial e temporal.

O contexto regional se completa com o Arco de Ponta Grossa (APG), um enxame de diques de direção preferencial entre N50-60W delimitado pelos alinhamentos estruturais-magnéticos de Guapiara (Ferreira et al. 1981) a nordeste e do Rio Piquiri a sudoeste (Fig. 1B). Sua região central é balizada pelos alinhamentos São Jerônimo-Curiúva e do Rio Alonzo
(Ferreira 1982b, Portela Filho \& Ferreira 2003). Suas extensóes são superiores a $600 \mathrm{~km}$, e as larguras variáveis entre 20 e 100 km (Ferreira 1982b, Portela Filho e Ferreira 2003).

A influência tectônica do APG é registrada do Devoniano, influenciando a sedimentação na Bacia do Paraná, com clímax durante a reativação Waldeniana, ao Juro-Cretáceo (Almeida 1980; Ferreira 1982b).

\section{MATERIAL E MÉTODOS}

\section{Dados aeromagnéticos}

O conjunto de dados aeromagnetométricos utilizado foi composto por oito levantamentos da base de dados de projetos aerogeofísicos do Brasil da Companhia de Pesquisa de Recursos Minerais - CPRM (www.cprm.gov.br). Os dados foram reduzidos do IGRF-International Geomagnetic Reference Field, de acordo com os parâmetros de aquisição (Tab. 1), micronivelados, continuados para cima $(1.500 \mathrm{~m})$ e interpolados por curvatura mínima (Briggs 1974), com uma célula quadrada de $500 \mathrm{~m}$. Foram integrados, resultando no mapa do campo magnético anômalo (CMA) (Fig. 3A).

A confecção do mapa do campo magnético anômalo reduzido ao polo (CMA-RTP) (Fig. 3B) foi elaborada com base nos dados reduzidos ao polo de cada projeto, conforme a localização e respectivas datas de aquisição, e depois integrados. Para atenuar os sinais de alta frequência espacial, a malha unificada CMA-RTP foi continuada para cima (2.000 e $5.000 \mathrm{~m})$, resultando, respectivamente, nos mapas das Figuras 4C e 4D. O mapa continuado para $5.000 \mathrm{~m}$ (CMA-RTP UW 5.000 m), observado na Figura 3D, constituiu a base da interpretação qualitativa.

Tabela 1. Especificações dos levantamentos aerogeofísicos na área de estudo.

\begin{tabular}{|c|c|c|c|c|c|c|c|c|}
\hline CPRM & Contratante & Projeto & Ano & $\begin{array}{l}\text { Espaçamento } \\
\text { das linhas } \\
\text { (m) }\end{array}$ & $\begin{array}{c}\text { Altura } \\
\text { de vôô } \\
\text { (m) }\end{array}$ & $\begin{array}{l}\text { Intervalo de } \\
\text { amostragem } \\
\text { (m) }\end{array}$ & $\begin{array}{c}\text { Linhas } \\
\text { (Total km) }\end{array}$ & $\begin{array}{c}\text { Área do } \\
\text { projeto }\left(\mathbf{k m}^{2}\right)\end{array}$ \\
\hline 1025 & CPRM & 8 - Serra do Mar Sul & 1975 & 1.000 & 150 & 60 & 49.880 & 48.600 \\
\hline 1039 & CPRM & 2 - SP-RJ Área SP & 1978 & 1.000 & 150 & 100 & 52.436 & 58.000 \\
\hline 2010 & NUCLEBRAS & $\begin{array}{l}7 \text { - Ponta Grossa - } \\
\text { Criciúma (Área I) }\end{array}$ & 1971 & 1.000 & 120 & 120 & 33.810 & 39.184 \\
\hline 4009 & PETROBRAS & $\begin{array}{l}1 \text { - Plataforma } \\
\text { Continental Sul }\end{array}$ & 1969 & 5.000 & 700 & 60 & 52.932 & 219.000 \\
\hline 4012 & PETROBRAS & 6 - Bacia do Paraná & 1973 & 7.000 & 1500 & 70 & 20.650 & 116.400 \\
\hline 4019 & PETROBRAS & 3 - Botucatu & 1980 & 2.000 & 450 & 100 & 25.745 & 46.000 \\
\hline 4023 & PETROBRAS & 5 - Rio Iguaçu & 1980 & 2.000 & 500 & 100 & 39.600 & 66.486 \\
\hline \multirow[t]{2}{*}{4025} & PETROBRAS & 4 - Rio Ivaí & 1981 & 2.000 & 450 & 66 & 25.726 & 48.840 \\
\hline & & & & & & Total & 300.779 & 642.510 \\
\hline
\end{tabular}




\section{Dados gravimétricos terrestres}

Os dados gravimétricos terrestres foram adquiridos ao longo de três transectas regionais NW-SE, perpendiculares às zonas de cisalhamento da Lancinha, Morro Agudo e Itapirapuã, tanto no embasamento como em seus prolongamentos sob a Bacia do Paraná. Como base dos levantamentos, foram utilizadas as estaçóes gravimétricas de Ponta Grossa, Curitiba e Jaguariaíva, integrantes da Rede Gravimétrica Científica do Estado do Paraná (Santos Jr. 2005).

Os dados foram adquiridos com o gravímetro Autograv CG3, fabricação Scintrex (Canadá), pertencente ao LPGA/ UFPR (Laboratório de Pesquisas em Geofísica Aplicada) nas transectas " $A$ ", "B" e "C', simultaneamente ao posicionamento realizado com um GPS 900 Leica (L1/L2), cedido pelo LabTopo - Laboratório de Topografia do Departamento de Engenharia Cartográfica da UFPR. Na transecta "D” foi empregado o gravímetro Autograv CG5, fabricação Scintrex
(Canadá), pertencente ao Pool de Equipamentos Geofísicos do Brasil (PEGBR), cedido pelo Observatório Nacional (ON), ao LPGA/UFPR. A aquisição consistiu na medida de valores da gravidade ao longo das transectas, com um espaçamento médio de $2 \mathrm{~km}$ adensado para $1 \mathrm{~km}$ no entorno das zonas de cisalhamento Itapirapuã, Morro Agudo e Lancinha. Os dados de produção são exibidos na Tabela 2.

\section{Análise qualitativa}

Sobre o mapa CMA-RTP UW 5.000 m (Fig. 3D), foram aplicados os seguintes métodos de realce de anomalias visando à interpretação do arcabouço magnético-estrutural da área de estudo: Amplitude do Sinal Analítico (ASA) (Nabighian 1972, 1974, Roest et al. 1992), Gradiente Horizontal Total (GHT) (Cordell \& Grauch 1985), Inclinação ou Fase do Sinal Analítico (ISA) (Miller \& Singh 1994), Gradiente Horizontal Total da Inclinação do Sinal Analítico (GHT-ISA)

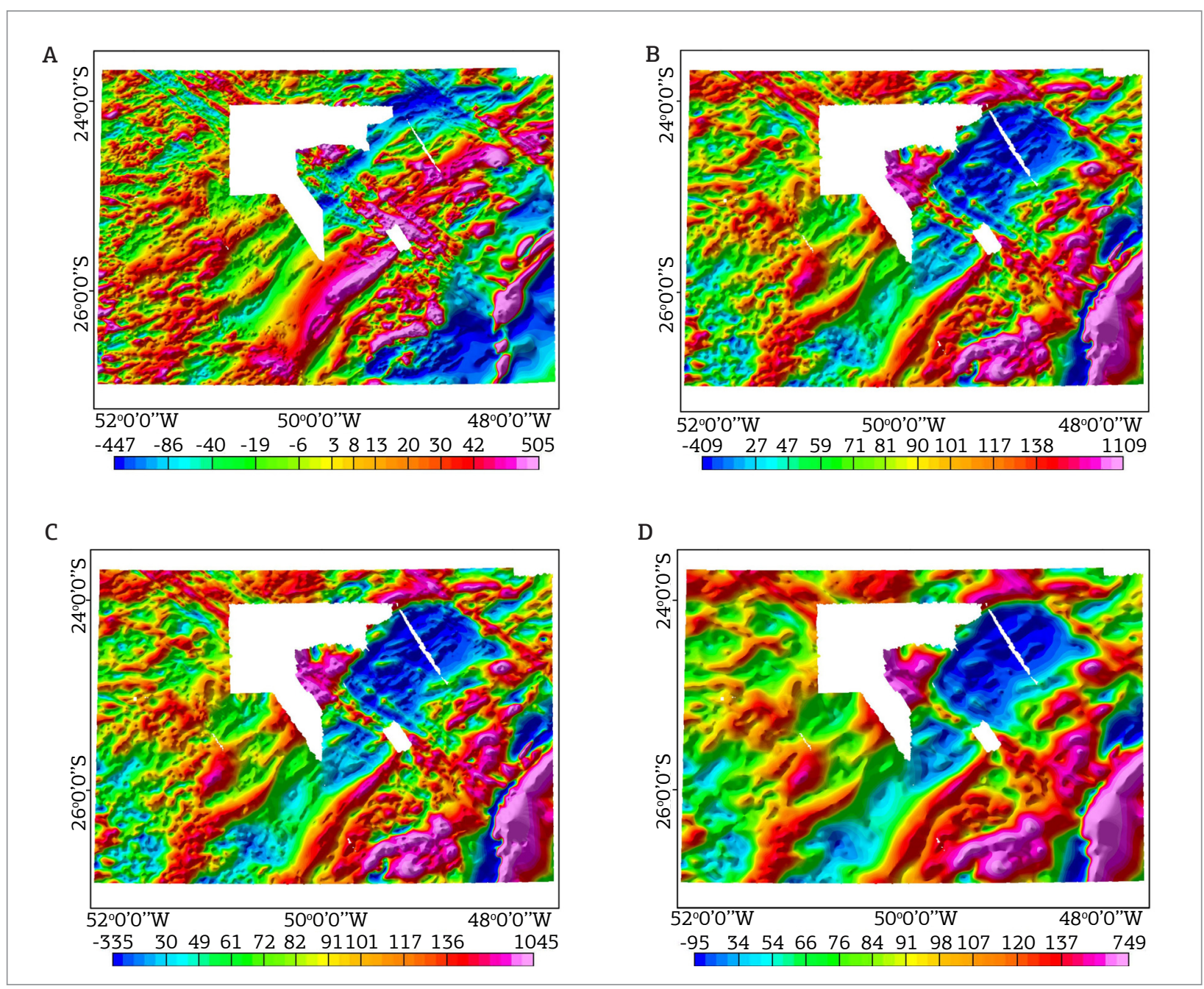

Figura 3. (A) Mapa do campo magnético anômalo (CMA) continuado para cima (1.500 m), (B) mapa do campo magnético anômalo reduzido ao polo (CMA-RTP UW $1.500 \mathrm{~m}$ ), (C) mapa do campo magnético anômalo RTP continuado para cima a 2.000 m (CMA-RTP UW 2.000 m), (D) mapa do campo magnético anômalo RTP continuado para cima a $5.000 \mathrm{~m}$ (CMA-RTP UW $5.000 \mathrm{~m})$. 
(Verduzco et al. 2004) e Inclinação do Sinal Analítico do Gradiente Horizontal Total (ISA-GHT) (Ferreira et al. 2010, 2013). A Figura 4 mostra os principais métodos de realce, suas relaçóes geométricas e respectivas equações.

\section{Análise semiquantitativa}

Tendo em vista a estimativa de profundidades das fontes anômalas e a relação de sua distribuição com a interpretação qualitativa, foi aplicada a deconvolução de Euler (Thompson 1982, Reid et al. 1990). As soluçóes de maior correspondência com a interpretação qualitativa foram obtidas com índice estrutural igual a 0 (contato), tolerância máxima de profundidade igual a $3 \%$ e tamanho da janela igual a 10 , equivalente a $5.000 \mathrm{~m}$.

No intuito de decompor o sinal magnético em níveis de profundidade distintos, foi realizada a análise do espectro de potência radial dos dados magnéticos. A observação do espectro possibilitou a separação do sinal nos seguintes intervalos:

- Fontes profundas - comprimentos de onda maiores que $32 \mathrm{~km}$ e profundidades entre 9 e $20 \mathrm{~km}$.

- Fontes intermediárias - comprimentos de onda entre 16 e $32 \mathrm{~km}$, com profundidades entre 7,4 e 9,2 km.

- Fontes rasas - comprimentos de onda entre 5,7 e $16 \mathrm{~km}$ e profundidades médias de $2,2 \mathrm{~km}$.
Com base nesses valores, foram aplicados filtros de corte de frequência, resultando no mapa de fontes profundas.

\section{Análise quantitativa}

A modelagem dos dados gravimétricos foi realizada com base em Talwani et al. (1959) e Talwani e Heirtzler (1964), utilizando o algoritmo descrito por Won e Beavis (1987). Os valores de densidade utilizados foram obtidos dos trabalhos de Rosales (2004) e de Telford et al. (1990).

A construção dos modelos gravimétrico-estruturais foi realizada com base na integração dos resultados das análises qualitativa e semiquantitativa, balizada pela distribuição das principais feiçôes geológicas da área de estudo.

Tabela 2. Dados de produçãodas transecas levantadas.

\begin{tabular}{l|c|c}
\hline Transectas & Extensão $\mathbf{( k m )}$ & Estações \\
\hline A & 215 & 100 \\
\hline B & 313 & 149 \\
\hline C & 425 & 135 \\
\hline Total & 953 & 384 \\
\hline
\end{tabular}

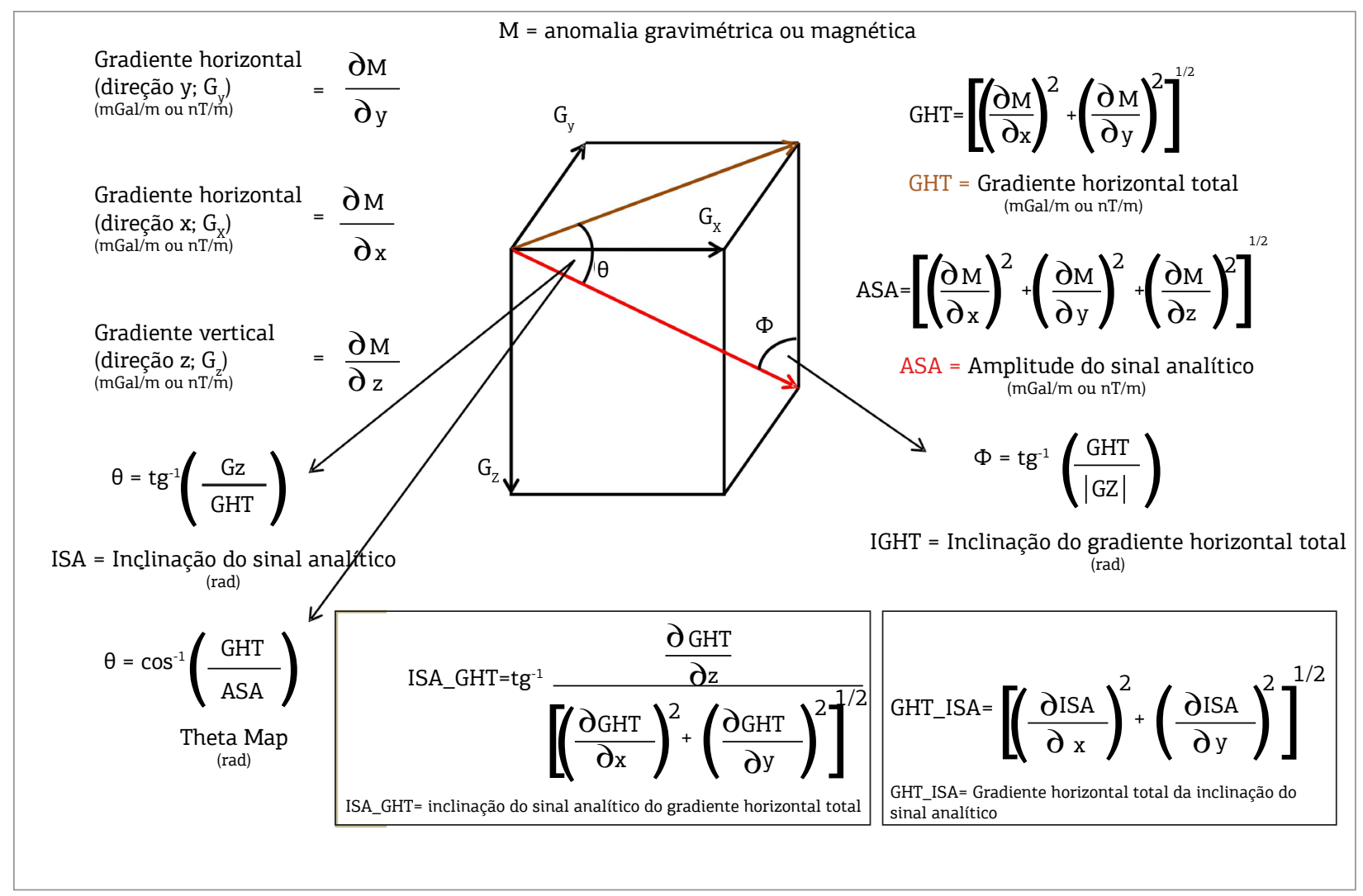

Figura 4. Principais métodos de realce de anomalias magnéticas e gravimétricas. 


\section{RESULTADOS}

\section{Arcabouço magnético-estrutural}

Os mapas resultantes da aplicação dos métodos de realce (Fig. 4) destacaram as estruturas regionais (Fig. 5), objeto deste estudo. Sua intepretaçáo possibilitou o traçado do arcabouço magnético-estrutural da área de estudo, exibidos sobre o ISA-GHT na Figura 7.

Os resultados indicam o prolongamento das estruturas do Cinturão Ribeira, sob a Bacia do Paraná, sugerindo sua convergência em subsuperfície num padrão sigmoidal (Fig. 6).

As zonas de cisalhamento Lancinha (Fig. 6A, b) — limite dos terrenos tectônicos Apiaí (Fig. 6A, A) e Curitiba (Fig. 6A, B) —, Alexandra (Fig. 6A, c) - limite entre os terrenos Luis Alves (Fig. 6A, C) e Paranaguá (Fig. 6A, D) —, e Itapirapuã (Fig. 6A, a) exibem uma resposta magnética correspondente com seu traçado em superfície.
O Lineamento Alto Iguaçu (Fig. 6A,1), sem relaçáo com feiçóes superficiais, mostra, além da alta amplitude $\mathrm{e}$ paralelismo com o trend NE-SW, continuidade sob a Bacia do Paraná.

Os lineamentos apresentados por Zalán et al. (1987) correspondem, ainda que parcialmente, ao arcabouço magnético-estrutural interpretado, como se nota com as seguintes feiçôes (Fig. 6B): Zona de Falha Lancinha-Cubatão (1), Zona de Falha Taxaquara (2), Falha de Jacutinga (3), Lineamento São Sebastião (4), Falha de São Jerônimo-Curiúva (5), Zona de Falha Curitiba-Maringá (6), Arco de Ponta Grossa (7) e Falha do Rio Alonzo (8). As soluçôes de Euler corroboram a interpretação qualitativa, apontando profundidades de fontes magnéticas superiores a $2.000 \mathrm{~m}$ para a Zona de Falha de Taxaquara, tanto no embasamento exposto como sob a Bacia do Paraná. A interpretação da convergência das zonas de cisalhamento Lancinha e Itapirapuã (ZCI) também foi validada pelas soluçóes de Euler, que, igualmente,
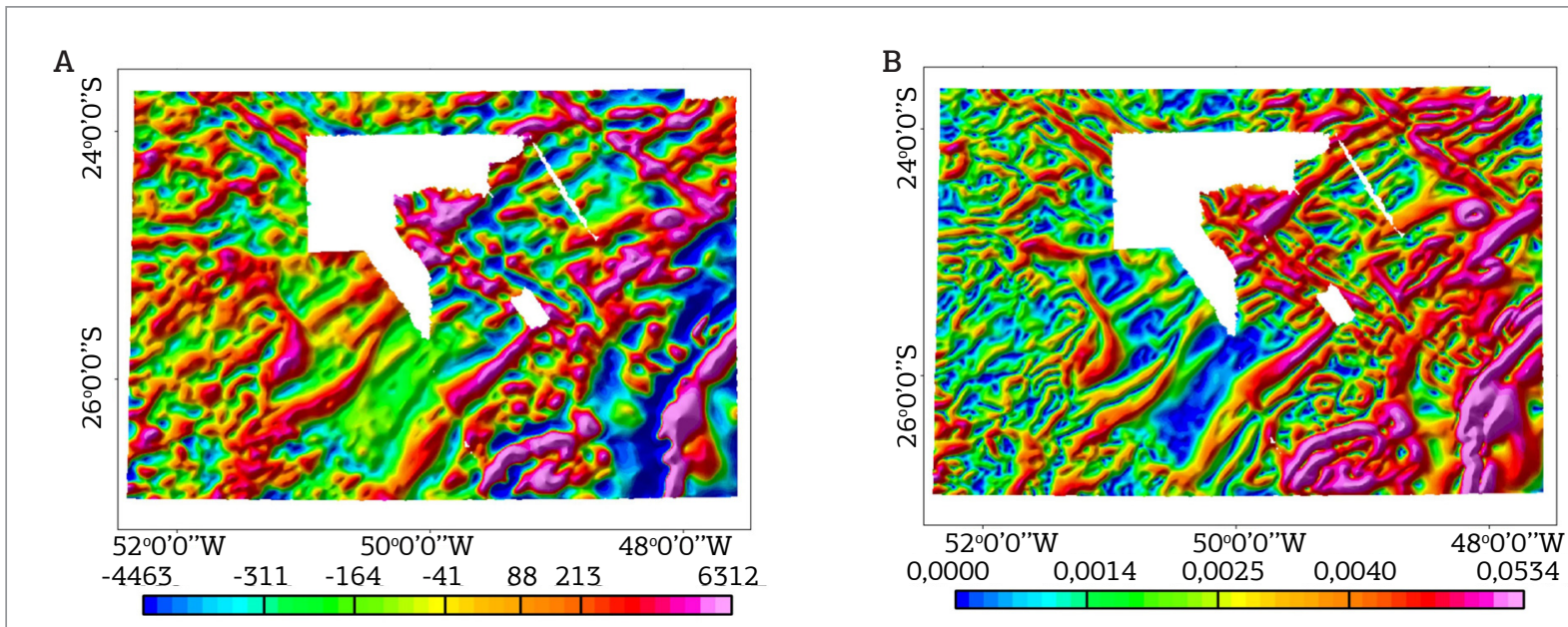

C

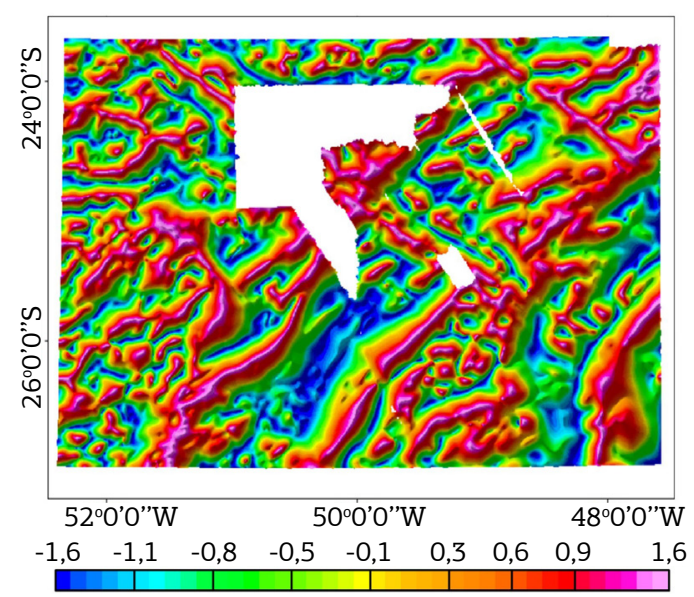

$\mathrm{D}$

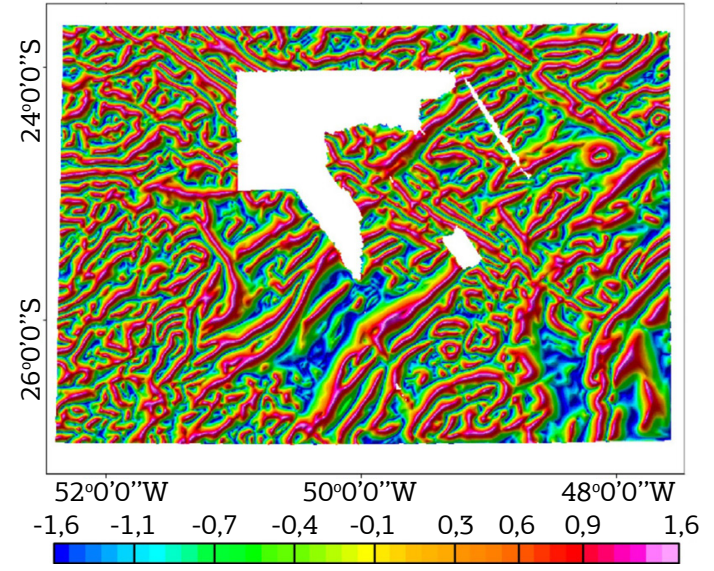

Figura 5. Mapas de realce de anomalias magnéticas calculados sobre o CMA-RTP UW 5.000 m:

(A) Gradiente vertical (GZ, nT/m), (B) Gradiente horizontal total (GHT, nT/m), (C) Inclinação do sinal analítico (ISA, rad) e (D) Inclinação do sinal analítico do gradiente horizontal total (ISA-GHT, rad). 
indicaram profundidades maiores que $2.000 \mathrm{~m}$ para ambas as estruturas. Para o Lineamento Alto Iguaçu (Fig. 6D, 3), foram estimadas profundidades de fontes maiores que 2.000 $\mathrm{m}$, tanto na área da bacia como no embasamento adjacente.

As anomalias do mapa magnético de fontes profundas (Fig. 6D) mostram correspondência tanto com os lineamentos de Zalán et al. (1987) como com feiçôes mapeadas em superfície. A anomalia 1 corresponde ao Complexo Batolítico Cunhaporanga, cuja proximidade com a Zona de Falha de Taxaquara (ZFT) sugere uma relação em profundidade. A anomalia 2 reflete o prolongamento da ZCL sob a bacia e a convergência com a ZCI em subsuperfície. As anomalias assinaladas com o número 3 indicam o prolongamento do Lineamento Alto Iguaçu e da ZCP sob a bacia. O Complexo Granulítico Luis Alves, o Lineamento do Rio Alonzo e o Complexo Alcalino de Jacupiranga se vinculam, respectivamente, às anomalias 4,5 e 6.

\section{Modelos gravimétricos}

Visando decompor o sinal gravimétrico em sinais de profundidades distintas, foi aplicada a separação regionalresidual pela análise do espectro 1-D. A partir da média dos comprimentos de onda, foram estabelecidos os seguintes valores de corte para as filtragens: acima de $37.144 \mathrm{~m}$ para
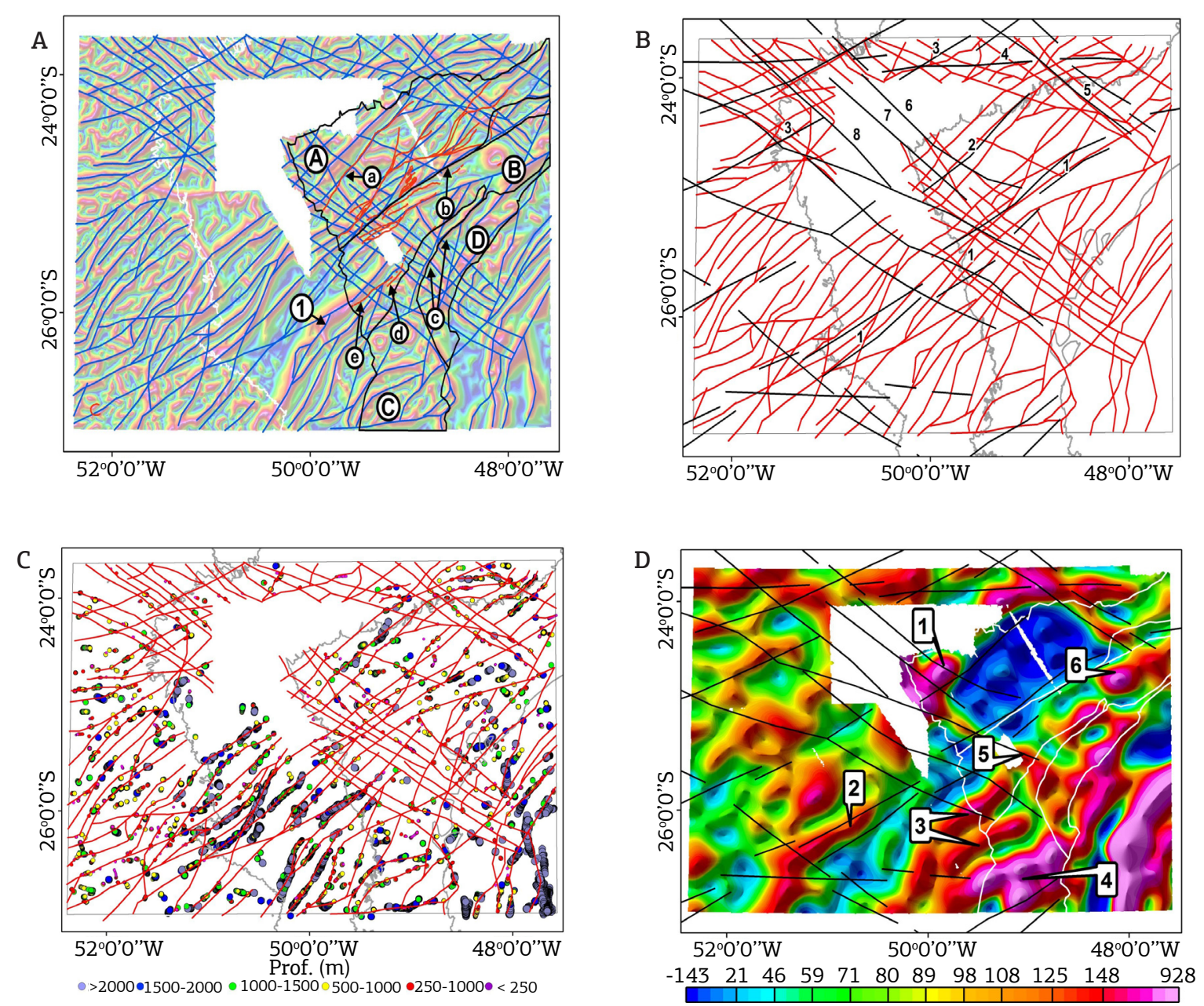

Terrenos: A - Terreno Apiaí, B - Terreno Curitiba, C - Terreno Luis Alves e D - Terreno Paranaguá. (preto). Zonas de cisalhamento (vermelho): a Itapirapuã, b - Lancinha, c - Alexandra, d - Piên e e - Mandirituba-Piraquara, 1 - Lineamento Alto Iguaçu;

1 - Zona de Falha Lancinha-Cubatão, 2 - Zona de Falha Taxaquara, 3 - Falha Jacutinga, 4 - Lineamento São Sebastião, 5 - Falha de São JerônimoCuriúva, 6 - Zona de Falha Curitiba-Maringá, 7 - Arco de Ponta Grossa, 8 - Falha Rio Alonzo;

Figura 6. Mapas de interpretação: (A) ISA-GHT com a interpretação do arcabouço magnético estrutural (linhas azuis). (B) Arcabouço magnético-estrutural (vermelho) sobreposto ao contorno do pré-cambriano e Fm. Serra Geral (cinza) e lineamentos de Zalán et al. (1987) (preto). (C) Arcabouço magnético estrutural (vermelho) sobrepostas as soluções de Euler, contorno do pré-cambriano e Fm. Serra Geral (cinza); (D) Mapa magnético de fontes profundas, entre 9 e $20 \mathrm{~km}$, com indicação dos lineamentos de Zalán et al. (1987). 
as fontes profundas, entre 37.144 e $3.763 \mathrm{~m}$ para as fontes intermediárias, e menores que $3.763 \mathrm{~m}$ para as fontes rasas.

Assim, foram elaborados dois modelos para cada transecta, um com base no sinal de fontes profundas (regional), e outro (residual) envolvendo as unidades aflorantes e seu embasamento (fontes intermediárias?). Os resultados das análises qualitativa e semiquantitativa foram incorporados aos modelos como informaçóes a priori.

Nos modelos regionais, as propriedades físicas e profundidade das camadas crustais foram baseadas em Bassini (1986) e Rosales (2004), os quais indicam para a crosta continental superior uma espessura de $11 \mathrm{~km}$, com densidade de $2,84 \mathrm{~g} / \mathrm{cm}^{3}$. A crosta continental inferior foi dividida em duas camadas: uma superior, entre 11 e $24 \mathrm{~km}$ de profundidade, com densidade de $2,98 \mathrm{~g} / \mathrm{cm}^{3}$; e outra inferior, entre 24 e $39 \mathrm{~km}$ de profundidade, com densidade de $3,09 \mathrm{~g} / \mathrm{cm}^{3}$. A interface crosta/manto foi posicionada a $39 \mathrm{~km}$ de profundidade, com densidade do manto estimada em $3,39 \mathrm{~g} / \mathrm{cm}^{3}$.

\section{Transecta A}

A anomalia regional da Transecta $\mathrm{A}$, realizada sobre as rochas paleozoicas da Bacia do Paraná, mostra uma alternância de altos e baixos gravimétricos, reflexo da variação de espessura crustal. A porção central concentra as menores amplitudes, enquanto os máximos são observados nas extremidades NW e SE (Fig. 7). As quebras de gradiente que limitam as anomalias correspondem às estruturas regionais apresentadas por Zalán et al. (1987).

$\mathrm{O}$ perfil inicia à NW com uma espessura crustal de $38,5 \mathrm{~km}$, com a primeira quebra de gradiente localizada entre a Falha do Rio Alonzo (FRA) e a ZFT (Zalán et al. 1987) relacionada a um aumento da espessura crustal $(41,0 \mathrm{~km})$ em direção ao centro do perfil. Essa feição corresponde a um baixo gravimétrico relativo, limitado pela ZFT e o prolongamento da ZCI.

Entre os prolongamentos da ZCI e da ZCL, se observa a porção de menor espessura crustal do perfil $(38 \mathrm{~km})$,
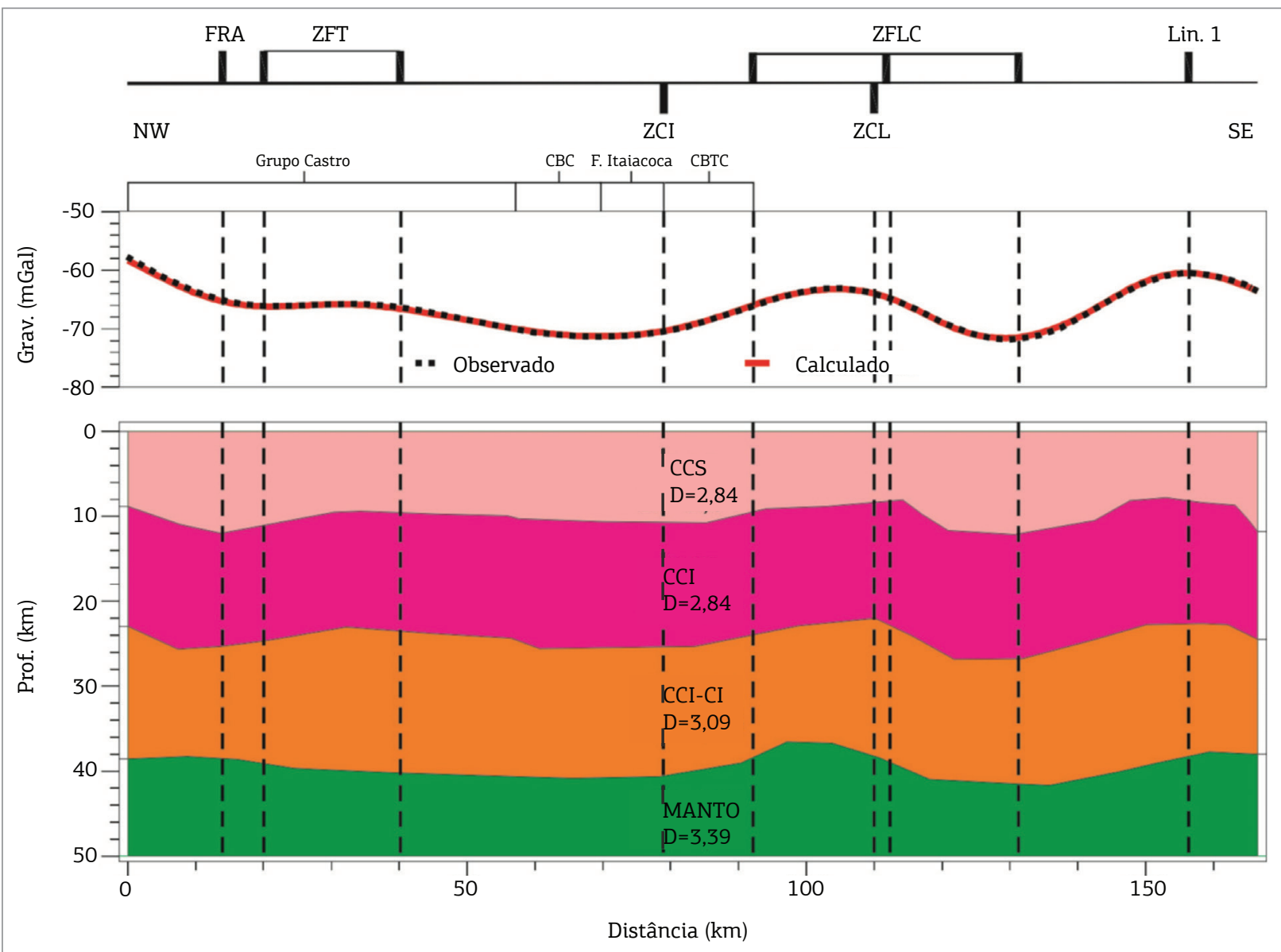

CCS - Crosta Continental Superior, CCI-CS - Crosta Continental Inferior, Camada Superior, CCI-CI - Crosta Continental Inferior, Camada Inferior. Principais estruturas: FRA - Falha do Rio Alonzo; ZFT - Zona de Falha de Taxaquara; ZCI - Zona de Cisalhamento Itapirapuã; ZFLC - Zona de Falha Lancinha Cubatão; ZCL - Zona de Cisalhamento Lancinha; ZFC - Zona de Falha Caçador; CBC - Complexo Batolítico Cunhaporanga; CBTC Complexo Batolítico Três Córregos; Lin.1 - Lineamento Alto Iguaçu.

Figura 7. Anomalia gravimétrica regional da transecta A (painel superior) e o modelo correspondente (painel inferior). 
correspondente a um alto gravimétrico relativo. À sudeste do prolongamento da ZCL, se verifica a maior espessura crustal da transecta, cerca de $42 \mathrm{~km}$, correspondente a um baixo gravimétrico $(-71,5 \mathrm{mGal})$. No extremo sudeste, é observado um alto relativo $(-60,5 \mathrm{mGal})$ relacionado à diminuição da espessura crustal $(37,9 \mathrm{~km})$, correspondente ao Lineamento Alto Iguaçu (Fig. 6A,1).

A anomalia residual (Fig. 8) inicia com uma alternância de altos e baixos entre de 1,6 e -3,2 mGal, possivelmente relacionada a variaçôes de espessura do Grupo Castro (indiviso), em profundidade. Em direção a SE, um alto gravimétrico $(2,2 \mathrm{mGal})$ pode ser relacionado a um alto do embasamento (Fig.10).

A porção central do perfil mostra uma série de três baixos gravimétricos relativos $(-4,5 ;-2,4$ e $-5,2 \mathrm{mGal})$ intercalados a dois altos (3,8 e 2,0 mGal). Essa assinatura, recorrente nos perfis "B" e "C" (Fig. 4), corresponde à resposta gravimétrica do prolongamento de unidades do embasamento adjacente sob a bacia. Os baixos gravimétricos corresponderiam aos complexos batolíticos Cunhaporanga (CBC) e Três Córregos (CBTC) e o Granito Passa Três (GPT), intercalados pelas rochas da Faixa Itaiacoca e rochas básicas associadas. Um alto do embasamento sobre o qual se prolonga a Formação Água Clara se reflete por um alto gravimétrico. O alto gravimétrico à sudeste do GPT foi relacionado a um alto do embasamento, seguido de um baixo subsequente correspondente, possivelmente, ao prolongamento da Sequência Votuverava, sob a bacia.

O segmento sudeste é marcado pela ZCL, limite entre os terrenos Apiaí e Curitiba, cuja resposta é um alto relativo
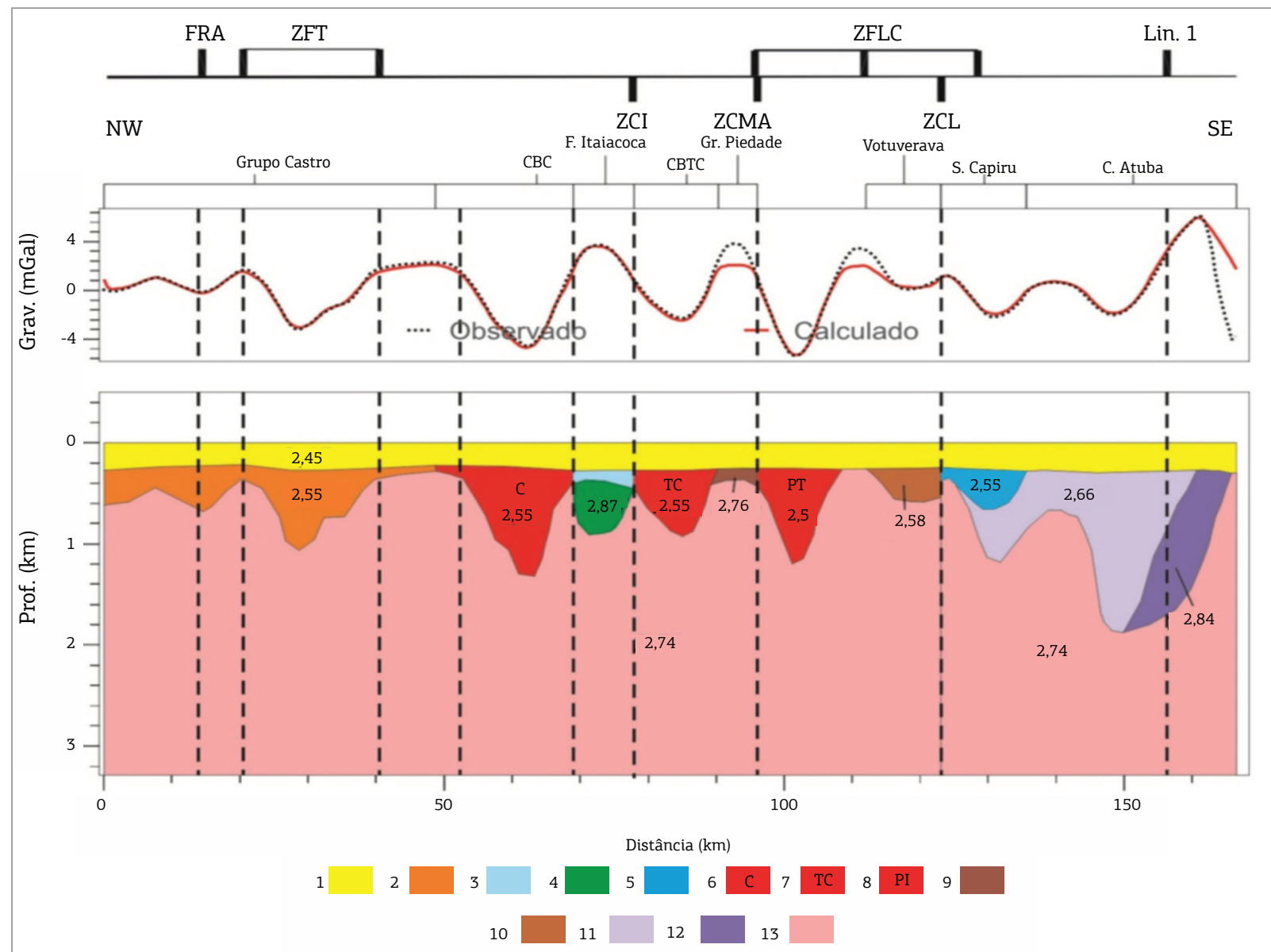

1 - Bacia do Paraná; 2 - Grupo Castro; 3 e 4 - Faixa Itaiacoca com rochas básicas associadas; 5 - Sequência Capiru; 6 - Complexo Batolítico Cunhaporanga; 7 - Complexo Batolítico Três Córregos; 8 - Granito Passa Três; 9 - Sequência Água Clara; 10 - Sequência Votuverava; 11 Complexo Gnáissico- migmatíticos Atuba; 12 - Suíte Granítica Cálcio-Alcalina Rio Piên; 13 - Embasamento. Principais Estruturas: FRA - Falha do Rio Alonzo; ZFT - Zona de Falha de Taxaquara; ZCI - Zona de Cisalhamento Itapirapuã; ZFLC - Zona de Falha Lancinha-Cubatão; ZCMA - Zona de Cisalhamento Morro Agudo; ZCL - Zona de Cisalhamento Lancinha; CBC - Complexo Batolítico Cunhaporanga; CBTC - Complexo Batolítico Três Córregos; Lin.1 - Lineamento Alto Iguaçu.

Figura 8. Anomalia gravimétrica residual da transecta A (painel superior) e modelo correspondente (painel inferior). 
discreto. A ocorrência de dois baixos gravimétricos relativos $(-2 \mathrm{mGal})$ intercalados por um alto $(0,7 \mathrm{mGal})$ caracterizaria a variação de espessura do Complexo Atuba. O extremo sudeste do perfil exibe a anomalia de maior amplitude, cerca de 6,2 mGal, relacionada ao Lineamento Alto Iguaçu (Fig. 6A,1).

\section{Transecta B}

O modelo regional da Figura 10 inicia a NW com um baixo gravimétrico relacionado à espessura crustal de cerca de $38 \mathrm{~km}$. À sudeste a espessura diminui, chegando a $35 \mathrm{~km}$, refletindo num alto gravimétrico expressivo $(41,5 \mathrm{mGal})$, no domínio do Terreno Apiaí (Fig. 9).

À sudeste da Falha de Castro (FC), observa-se um baixo gravimétrico $(-54 \mathrm{mGal})$ relacionado a um espessamento da crosta $(37 \mathrm{~km})$. O segmento central mostra um alto gravimétrico relativo $(-49,2 \mathrm{mGal})$ vinculado a uma zona de afinamento crustal $(34 \mathrm{~km})$ limitada pela ZFT e associada à ZCI.
O baixo gravimétrico subsequente (-63,3 $\mathrm{mGal})$ é limitado à NW pela ZCI e à SE pela Zona de Cisalhamento Morro Agudo (ZCMA), e reflete uma região de espessamento crustal da ordem de $38,7 \mathrm{~km}$.

O segmento sudeste do perfil é marcado por um alto gravimétrico $(-47 \mathrm{mGal})$, limitado pela ZCMA e a Falha do Passaúna (FP), seguido por um baixo $(-53,5 \mathrm{~m} \mathrm{Gal})$, balizado à SE pela Zona de Cisalhamento Mandirituba-Piraquara (ZCMP). Essas feiçóes são associadas, respectivamente, a uma zona de afinamento $(34,5 \mathrm{~km})$, seguida de um espessamento crustal $(37 \mathrm{~km})$.

Um alto expressivo no extremo sudeste do perfil $(-42,12 \mathrm{mGal})$, relacionado a uma espessura crustal de $35 \mathrm{~km}$, guarda correspondência com a ZCP, limite entre os terrenos Apiaí e Luís Alves.

A anomalia residual da Figura 10 mostra a distinção do sinal no domínio da Bacia do Paraná, com amplitudes menores $(0,8$ a $-1,8 \mathrm{mGal})$, e o domínio do Cinturão Ribeira,

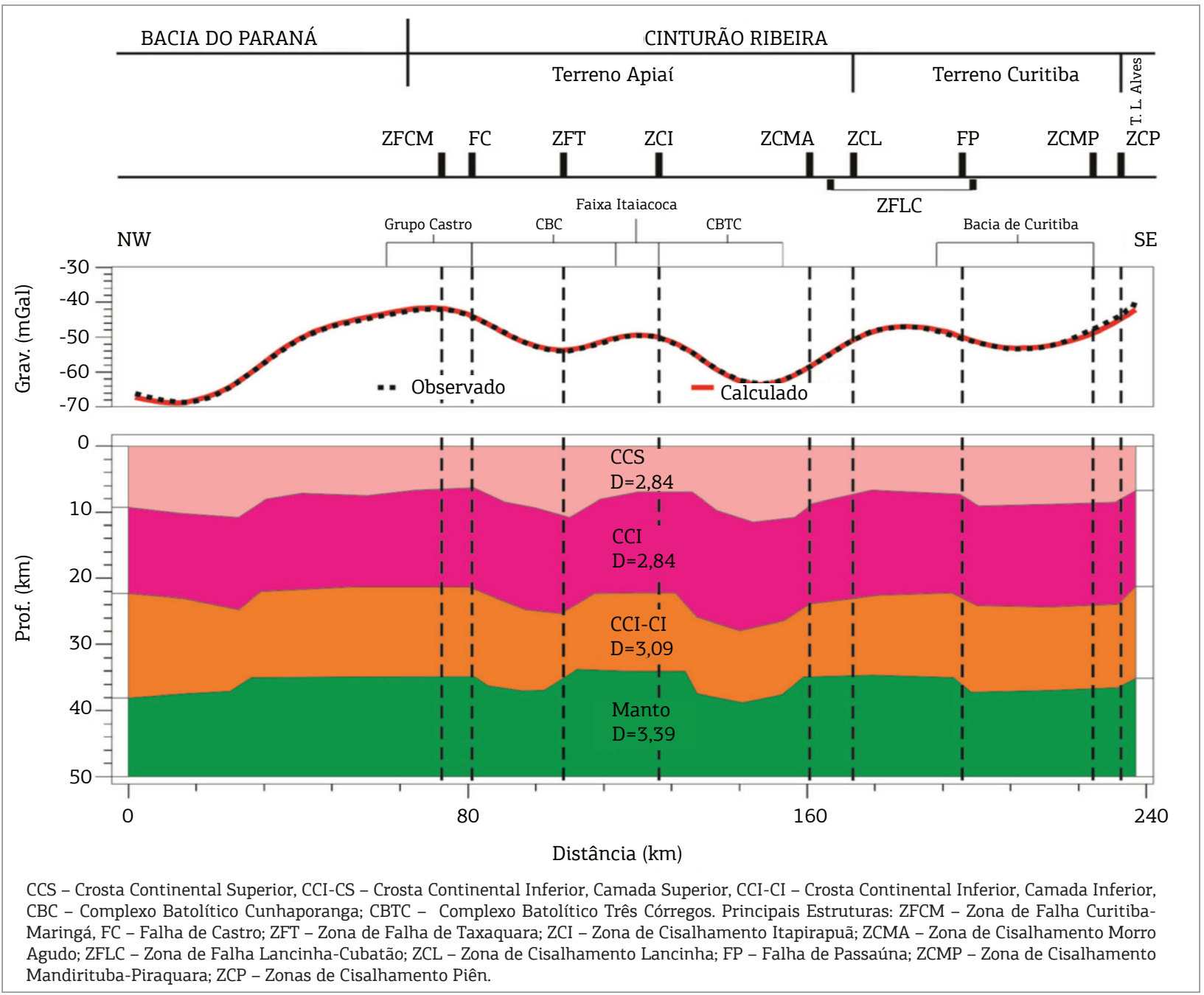

Figura 9. Anomalia gravimétrica regional de transecta B (painel superior) e o modelo correspondente (painel inferior). 
onde as amplitudes são mais altas, variando de $-5,6$ a $7,4 \mathrm{mGal}$. A variação no segmento NW do perfil é atribuída à variação de composição e espessura do Grupo Castro, tanto sob a bacia como em sua porção aflorante.

A porção central do perfil é marcada por dois baixos gravimétricos intercalados a um alto, padrão semelhante ao observado nas transecta "B" e "D". Tal variação é relacionada à intercalação da Faixa Itaiacoca (FI), associada a rochas básicas, correspondente ao alto, com os complexos batolíticos Cunhaporanga (CBC) e Três Córregos (CBTC), relacionados aos baixos gravimétricos. $\mathrm{O}$ contato da Faixa Itaiacoca com o CBTC, dado em superfície pela ZCI, é marcado pela quebra do gradiente no sinal gravimétrico. $\mathrm{O}$ alto consecutivo é associado à variação das relaçôes de contato do CBTC e Sequência Água Clara com o embasamento.
À SE da ZCMA, um baixo gravimétrico limitado à SE pela ZCL é a resposta conjunta da Sequência Votuverava e do Granito do Cerne. O alto subsequente (3,6 mGal) foi relacionado à associação da Sequência Capiru com o Complexo Atuba, sucedido por um baixo gravimétrico $(-5,3 \mathrm{mGal})$ na região da Bacia de Curitiba, refletindo, talvez, uma variação composicional do Complexo Atuba, coincidente com o prolongamento da Falha do Passaúna (FP).

A porção $S E$ do perfil exibe um baixo gravimétrico ladeado por dois altos, atribuídos, respectivamente, à Suíte Granítica Cálcio-alcalina Rio-Piên e suas associações com lentes ultramáficas em subsuperfície. As zonas de cisalhamento Mandirituba-Piraquara (ZCMP) e ZCP constituem os limites dessa unidade, e a última separa os terrenos Curitiba e Luís Alves.

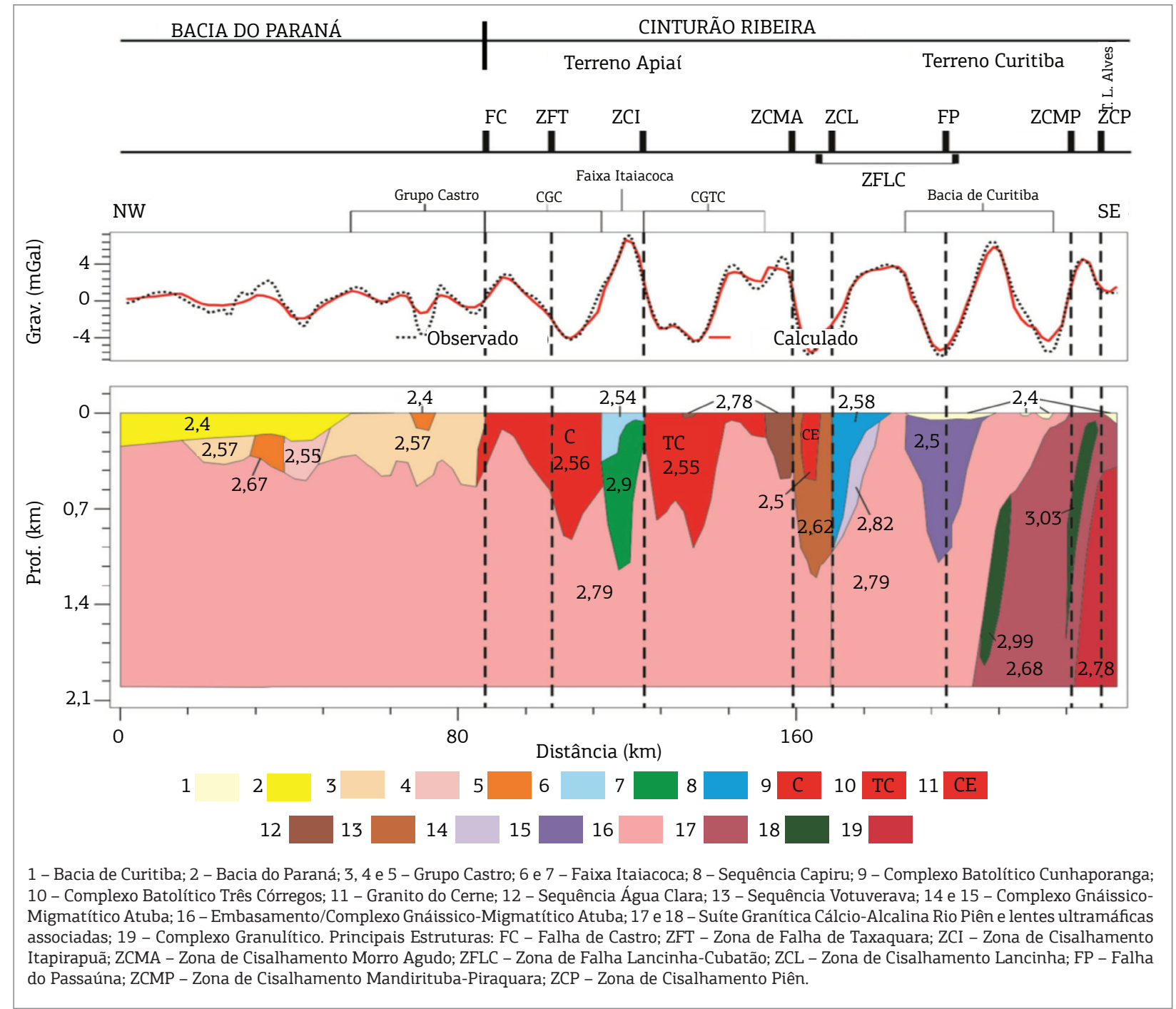

Figura 10. Anomalia gravimétrica residual da transecta B (painel superior) e modelo correspondente (painel inferior). 


\section{Transecta C}

A anomalia regional da transecta $\mathrm{C}$ revela três patamares com aumento de amplitude de NW para SE, relacionados a um afinamento crustal, com variaçóes de espessura balizadas pelas zonas de cisalhamento (Fig. 11).

O primeiro patamar mostra uma variação de espessura crustal entre 39,8 e 35,8 km, separada do segundo segmento pela ZCI. Neste último, dois altos relativos intercalados por um baixo estáo associados, respectivamente, a porçóes mais delgadas da crosta $(36,7$ e $34,3 \mathrm{~km})$ e a uma porção de maior espessura $(37,7 \mathrm{~km})$ limitada à SE pela ZCMA.

O terceiro segmento, limitado pela ZCL, mostra o maior gradiente do perfil, com uma variação de $81 \mathrm{mGal}(-46$ a $35 \mathrm{mGal}$ ) em cerca de $30 \mathrm{~km}$ de extensão. Essa resposta reflete a variação de espessura crustal, de $42 \mathrm{~km}$, entre a ZCL e ZCMP, para 22,6 km, nas proximidades da ZCP. No Terreno Luís Alves, limitado à NW pela ZCP, a espessura volta a aumentar, variando de 25,0 a $30,5 \mathrm{~km}$.
A anomalia residual da transecta $\mathrm{C}$ mostra dois segmentos limitados pela ZCL, onde, à NW, a amplitude do sinal varia entre $-4,6$ e 6,2 $\mathrm{mGal}$ com grande comprimento de onda, e, à SE, oscila de $-26,5$ a $23,9 \mathrm{mGal}$, com uma frequência maior (Fig. 12).

O primeiro segmento, à NW, mostra um alto gravimétrico relativo relacionado à Bacia do Paraná, resposta do prolongamento do Grupo Castro em subsuperfície. As anomalias subsequentes mostram dois baixos gravimétricos intercalados a um alto relativo $(3 \mathrm{mGal})$ correspondentes ao Complexo Batolítico Cunhaporanga (CBC).

A resposta da borda SE do CBC, seguida pela Faixa Itaiacoca (FI) e o Complexo Batolítico Três Córregos, reproduz a assinatura observada nas transectas "A" e "B", discutida anteriormente. O contato da FI com o CBTC é marcado por um baixo relativo.

A ZCMA, à sudeste do CBTC, mostra um pico positivo relacionado a um alto do embasamento sob a Sequência

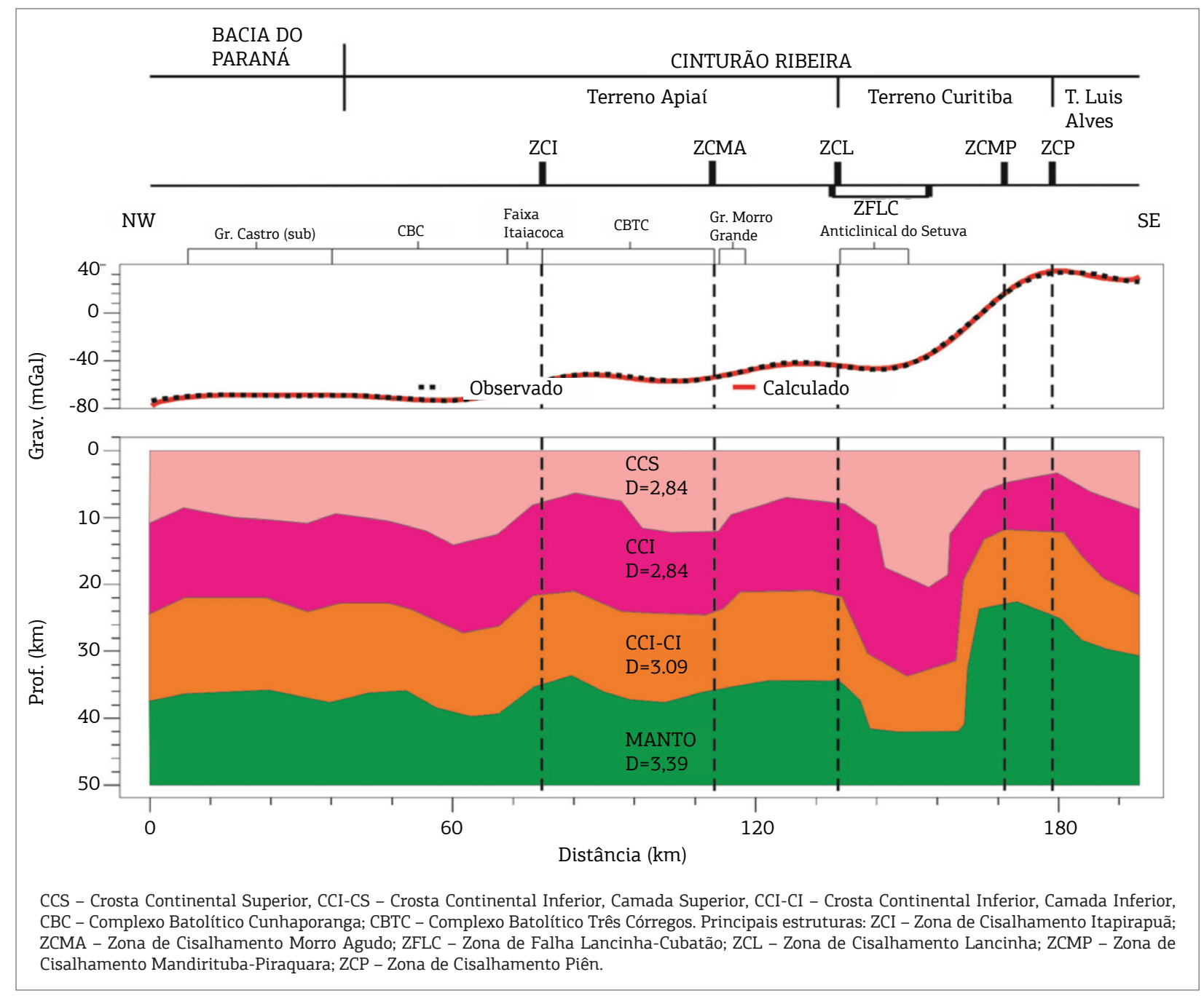

Figura 11. Anomalia gravimétrica regional de transecta $C$ (painel superior) e o modelo correspondente. 
Água Clara. O baixo subsequente, relacionado à resposta da Sequência Votuverava e do Granito Morro Grande, é limitado à NW pela ZCMA e à SE pela ZCL.

$\mathrm{O}$ segmento à SE da ZCL exibe dois altos gravimétricos relativos intercalados por um baixo, associados às variaçóes de espessura da Sequência Capiru e de composição do Complexo Atuba (CA). O baixo gravimétrico ulterior (-21,3 mGal) foi relacionado a possíveis variaçóes composicionais do Complexo Atuba nas proximidades da Bacia de Curitiba. Um alto gravimétrico associado ao prolongamento da Suíte Rio Piên e lentes ultramáficas associadas sob o Terreno Curitiba à NW marca a borda SE deste último. O baixo relativo subsequente $(-7 \mathrm{mGal})$ foi relacionado ao Granito Graciosa associado à Suíte Rio Piên, limitada à SE pela ZCP, limite com o Terreno Luís Alves, cuja resposta mostra um alto gravimétrico no extremo SE.

\section{DISCUSSÃO}

Além do afinamento crustal de NW para SE, observado em outros trabalhos (Rosales 2004), os modelos gravimétricos corroboram a proposta de sobreposição do Terreno Curitiba ao Terreno Luís Alves (Mantovani et al. 1989).

A distribuição das unidades e a configuração das camadas crustais se mostram compatíveis com o modelo de Basei et al. (1992), que interpretam o quadro tectônico atual como resultado da colagem dos Terrenos Luís Alves e Curitiba na margem oeste do Gondwana, entre o Neoproterozoico e o Cambriano, numa subducção do tipo A. Nesse contexto, a ZCL representaria uma sutura, mergulhando para NW sob o Terreno Apiaí (Basei et al. 1998). O adelgaçamento da crosta de NW para SE em direção ao Terreno Luís Alves

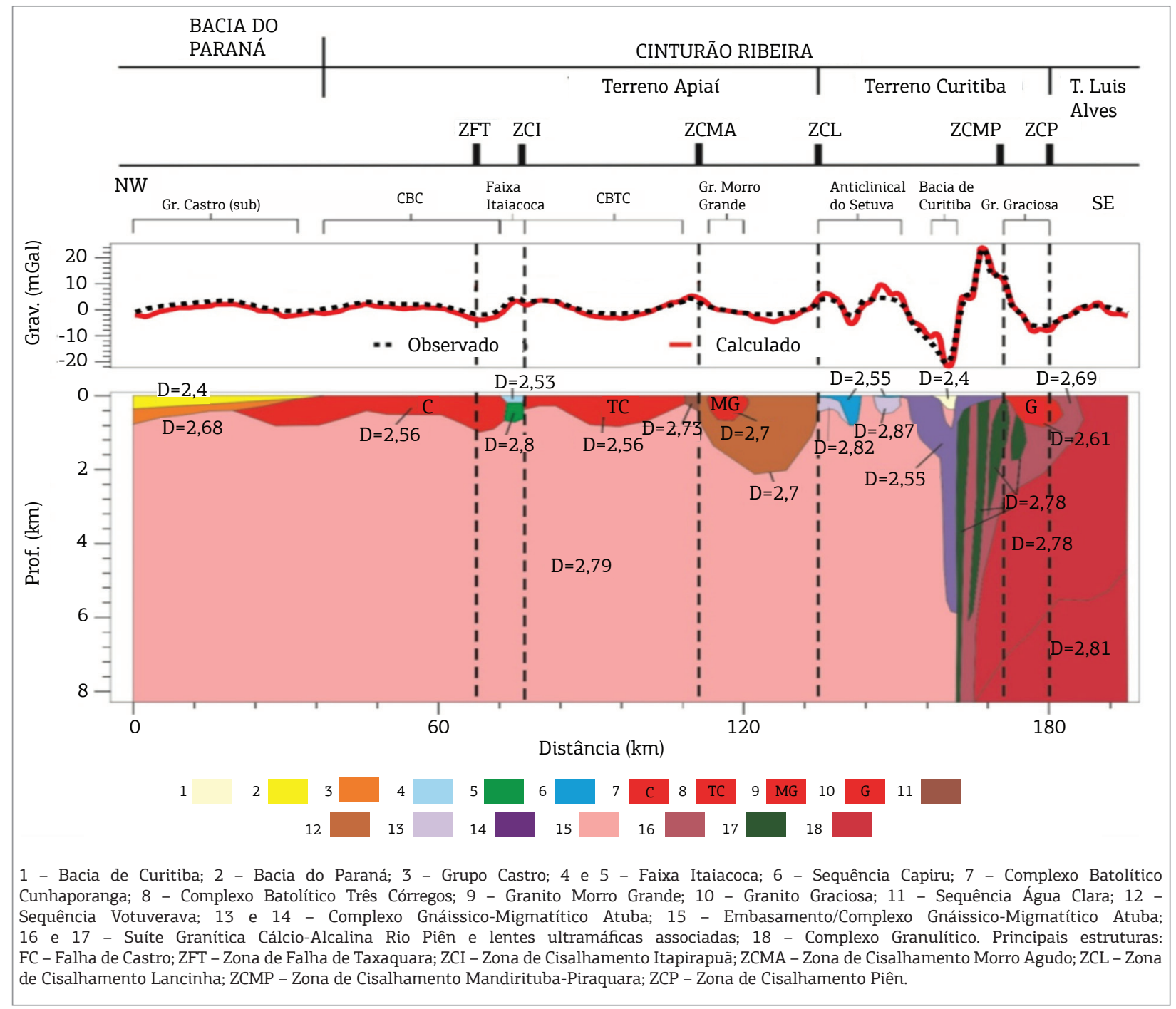

Figura 12. Anomalia gravimétrica residual da transecta C (painel superior) e modelo correspondente. 
apresentado pelos autores (Fig. 13) se harmoniza aos modelos apresentados.

No Terreno Apiaí, a variação da espessura crustal é marcada pela ZCI em associação com a Faixa Itaiacoca e a ZCMA. A assinatura geofísica (magnética e gravimétrica) relacionada à ZCI, observada nos modelos, permite sua interpretação como uma descontinuidade crustal. Basei et al. (1998) relacionam essa estrutura com o limite da borda leste do Cráton Paranapanema sob o Terreno Apiaí.

Os modelos sugerem que a ZCL, limite entre os terrenos Apiaí e Curitiba, configura um dos marcos de variação de espessura crustal, com mergulho vertical ou subvertical para NW. Na proposta apresentada por Basei et al. (1998), a ZCL exibe mergulhos relativamente mais baixos para NW, sob o Terreno Apiaí, destoando dos modelos gravimétricos apresentados.
Faleiros (2008) apresenta a ZCL como uma estrutura gerada pela reativaçáo de uma antiga zona de sutura, não correspondendo atualmente a uma sutura característica. A ausência da assinatura geofísica correspondente seria explicada pela progressão da transcorrência e a consequente alteração de sua resposta (Castro et al. 2014). Assim, a ZCL seria o testemunho de uma colisão neoproterozoica, modificada pela progressão do cisalhamento, configurando atualmente o limite entre os terrenos Curitiba e Apiaí como uma zona de cisalhamento predominantemente destral.

Dessa forma, o modelo de Basei et al. (1992, 1998), acrescido da proposta de Faleiros (2008) para a evolução da ZCL, seria compatível com os modelos apresentados. A Figura 14 sintetiza essa intepretação.

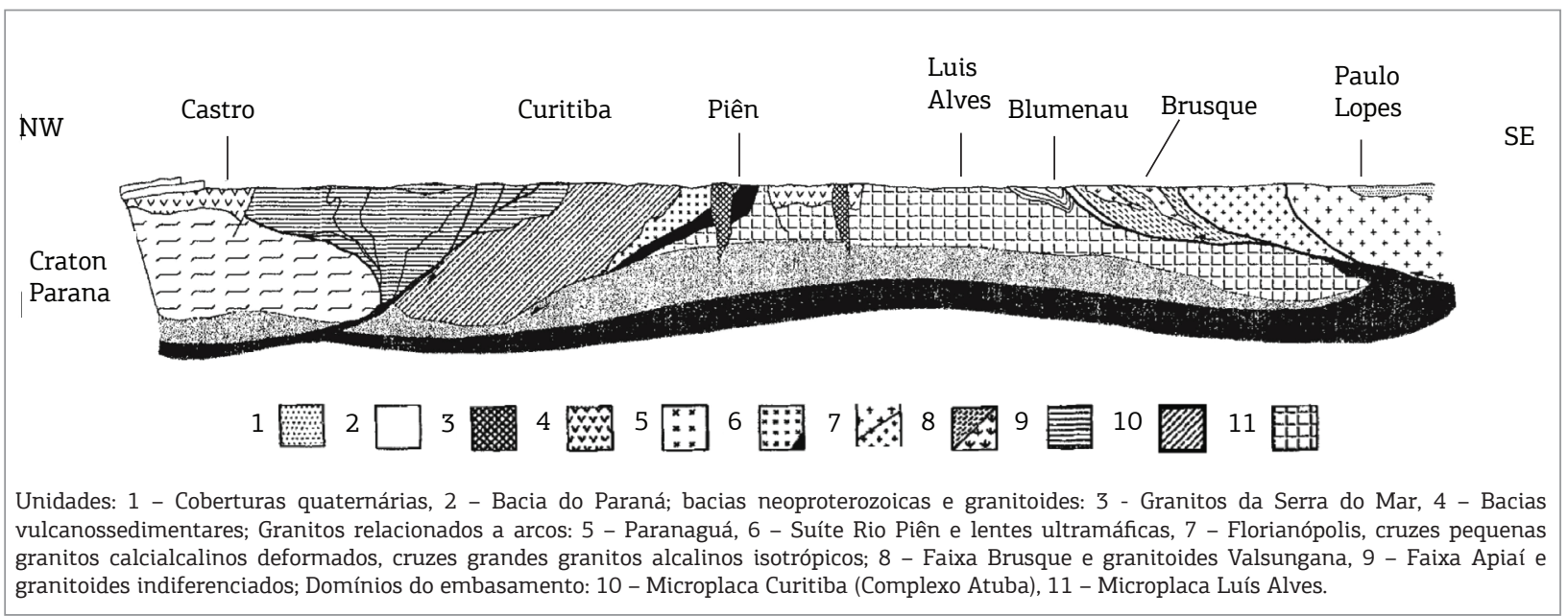

Figura 13. Perfil geológico esquemático dos terrenos pré-cambrianos do Sul do Brasil (modificado de Basei et al. 1998).

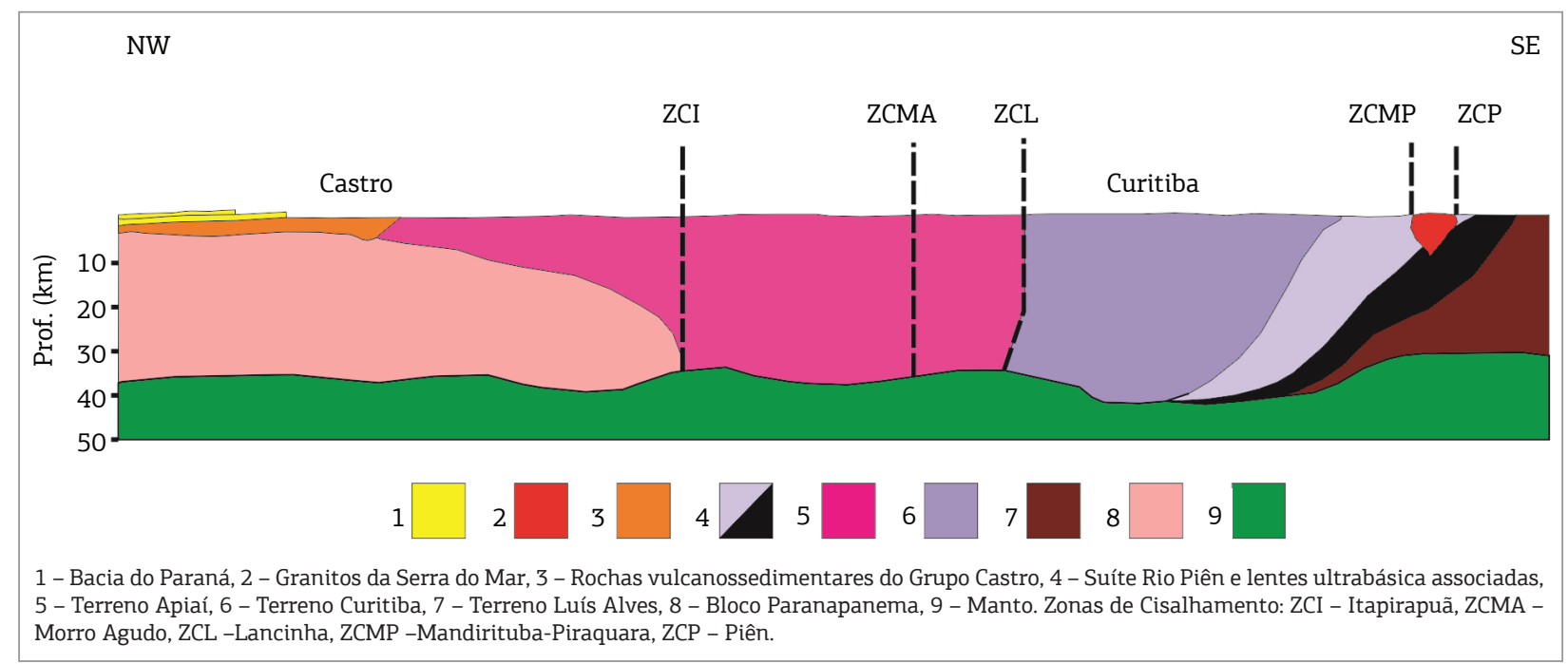

Figura 14. Perfil geológico esquemático da porção meridional do Cinturão Ribeira e regiões adjacentes modificado de Basei et al. (1998). 


\section{CONCLUSÕES}

Os lineamentos do arcabouço-magnético estrutural, gerado com base nos mapas de realce, mostraram correspondência com as zonas de cisalhamento Itapirapuá, Morro Agudo, Lancinha, Alexandra e Serra Negra, além dos propostos por Zalán (et al. 1987). Revelaram também que estruturas como a Zona de Falha de Taxaquara e as zonas de cisalhamento Itapirapuá, Morro Agudo e Lancinha, aflorantes no embasamento, se propagam sob a Bacia do Paraná. O prolongamento dos lineamentos sugere uma conexão em subsuperfície entre a ZCI, ZCMA e ZCL, num padrão sigmoidal.

As soluçóes de Euler, além de atestarem a interpretação do arcabouço, estimaram profundidades maiores que $2.000 \mathrm{~m}$ para a Zona de Falha de Taxaquara e as zonas de cisalhamento Itapirapuá, Morro Agudo, Lancinha e Mandirituba-Piraquara.

A recorrência de assinaturas gravimétricas nos perfis indica o prolongamento de unidades aflorantes no embasamento, como os complexos batolíticos Cunhaporanga e Três Córregos, e a Faixa Itaiacoca sob a bacia.

Os modelos gravimétricos indicam um afinamento crustal de NW para SE, balizado pelas zonas de cisalhamento, limitando segmentos de espessura crustal distintas, sendo o primeiro definido da Bacia do Paraná até a ZCI, com espessura crustal entre 33 e $38 \mathrm{~km}$, e um segundo entre a ZCI e a ZCL, com variação de 34 a $38 \mathrm{~km}$.

Um terceiro segmento, relacionado ao Terreno Curitiba, é limitado pela ZCL e a ZCP, com espessura crustal entre 24 e $43 \mathrm{~km}$, e o quarto segmento seria relacionado ao Terreno Luís Alves, em sua porção subjacente à borda leste do Terreno Curitiba, com espessura crustal entre 30 e $34 \mathrm{~km}$.

Os modelos indicam que a transição do Terreno Curitiba para o Terreno Luís Alves, marcada pela Suíte Rio Piên, associada em subsuperfície com lentes ultrabásicas, mergulha para NW sob a borda Leste do Terreno Curitiba. Os resultados corroboram a caracterização dessa estrutura como uma zona de sutura. O Lineamento Alto Iguaçu parece estar associado a esse limite.

\section{AGRADECIMENTOS}

Os autores agradecem à Petróleo Brasileiro S.A. (Petrobras) o financiamento da pesquisa através do Projeto Falhas, Campos de Esforços e Fluxo de Fluidos. Agradecem também à CPRM (Serviço Geológico do Brasil) pelos dados aeromagnéticos. L.G. de Castro e F.J.F. Ferreira agradecem, respectivamente, a CAPES pela Bolsa de Doutorado e ao CNPq pela Bolsa de Produtividade em Pesquisa (processo $\left.\mathrm{n}^{\circ} 305810 / 2010-3\right)$.

\section{REFERÊNCIAS}

Almeida F.F.M. 1980. Tectônica da Bacia do Paraná no Brasil. São Paulo, Instituto de Pesquisas Tecnológicas do Estado de São Paulo S/A. 187 p. (IPT. Relatório, 14.091).

Almeida F.F.M., Amaral G., Cordani U.G., Kawashita K. 1973. The Precambrian evolution of the South America cratonic margin south of the Amazon River In: Nairm E.M., Stehli F.G. (eds.). The Ocean basins and margins. New York, Plenum, p. 411-446.

Almeida F.F.M., Hasui Y., Brito Neves B.B., Fuck R.A. 1981. Brazilian structural provinces: an introduction. Earth-Science Reviews, 17(1/2):1-29

Basei M.A.S., Siga Jr. O., Machiavelli A., Mancini F. 1992. Evolução tectônica dos terrenos entre os Cinturões Ribeira e Dom Feliciano (PR - SC). Revista Brasileira de Geociências, 22(2):216-221.

Basei M.A.S., Mcreath I., Siga Jr. O. 1998. The Santa Catarina Granulite Complex of Southern Brazil: a review. Gondwana Research, 1(3-4):383-391.

Basei M.A.S., Frimmel H.E., Nuttman A.P. Preciozzi F. 2008. West Gondwana amalgamation based on detrital zircon ages from Neoproterozoic Ribeira and Dom Feliciano belts of South America and comparison with coeval sequences from SW Africa. In: Pankhurst R.J., Trow R.A.J., Brito Neves B.B., De Witt. (eds.) West Gondwana: Pre-Cenozoic Correlations Across the South Atlantic Region, London, Geological Society, Special Publication, 294 p., p. 239-256.

Bassini A.M. 1986. Levantamentos sismográficos na região sudeste do Brasil. MS Dissertation, Instituto de Astronomia, Geofísica e Ciências Atmosféricas, Universidade de São Paulo, São Paulo, 162 p.
Bizzi L.A., Schobbenhaus C., Vidotti R.M., Gonçalves J.H. 2001. Geologia, tectônica e Recursos Minerais do Brasil: Sistemas de Informações Geográfica - SIG e Mapas. Escala 1:2.500.000. Brasília, CPRM.

Briggs I.C. 1974. Machine Contouring Using Minimum Curvature. Geophysics, 39(1):39-48

Brito Neves B.B., Fuck R.A., Cordani U.C., Thomaz Filho A. 1984. Influence of basement structures on the evolution of the major sedimentary basis of Brazil: A Case of Tectonic Heritage. Journal of Geodynamics, 1:495-510.

Campanha G.A.C. \& Sadowski G.R. 1999. Tectonics of the Southern Portion of the Ribeira Belt (Apiaí Domain). Precambrian Research, 98:31-51.

Campanha G.A.C. 2002. O papel do sistema de zonas de cisalhamento transcorrentes na configuração da porção meridional da Faixa Ribeira. Tese de livre docência, Instituto de Geociências, Universidade de São Paulo, São Paulo, 105 p.

Castro L.G., Ferreira F.J.F., Cury L.F., Soares P.C., Lopes A.P., Oliveira M.J. 2014. Caracterização geofísica da Zona de Cisalhamento Lancinha no Estado do Paraná, Sul do Brasil, Brasil. Revista Geociências USP Série Científica, 14(4):3-18.

Cordani U.G., Neves B.B.B., Fuck R.A., Porto R., Thomaz Filho A., Cunha F.M.B. 1984. Estudo preliminar de integração do Pré-Cambriano com os eventos tectônicos das bacias sedimentares brasileiras. Rio de Janeiro, Petrobras, Série Ciência-Técnica-Petróleo, 15, 70 p. 
Cordell L. \& Grauch J. S. 1985. Mapping basement magnetization zones from aeromagnetic data in the San Juan Basin, New Mexico. In: SEG, 52nd Annual International Meeting, Expanded Abstracts, p. 246-247.

Cooper G. R. J. \& Cowan D. R. 2006. Enhancing potential field data using filters based on the local phase. Computers \& Geosciences, 32(10):1585-1591

Cury L.F. 2009. Geologia do Terreno Paranaguá. Tese de Doutorado, Instituto de Geociências, Universidade de São Paulo, São Paulo, 202 p.

Faleiros F.M. 2008. Evolução de terrenos tectono-metamórficos da Serrania do Ribeira e Planalto Alto Turvo (SP,PR). Tese de Doutorado, Instituto de Geociências, Universidade de São Paulo, São Paulo, $318 \mathrm{p}$

Ferreira F.J.F., Moraes R.A.V., Ferrari M.P., Vianna R.B. 1981 Contribuição ao estudo do Alinhamento Estrutural do Guapiara. In: Simpósio Regional de Geologia, SBG Curitiba, Atas..., p. 226-240.

Ferreira F. J. F. 1982a. Alinhamentos Estruturais - Magnéticos da Região Centro Oriental da Bacia do Paraná - Reavaliação da Potencialidade e Prospectividade em Hidrocarbonetos. São Paulo: Consórcio CESP-IPT - Paulipetro, 23 p.

Ferreira F. J. F. 1982b. Integração de Dados Aeromagnéticos e Geológicos: Configuração e Evolução Tectônica do Arco de Ponta Grossa. Dissertação de Mestrado, Instituto de Geociências, Universidade de São Paulo, São Paulo, 186 p.

Ferreira F.J.F., Galli V.L., Monma R. 1988. Modelo gravimétrico do perfil Itapeva-Barra do Turvo, região centro-oriental da Faixa Apiaí. In: Campanha G.A.C. (coord.) Avaliação preliminar da geologia das folhas (1:50.000) de Taquaral, Mina do Espírito Santo, Ribeirão Itacolomi, Serra do Aboboral, Jacupiranga, Rio Guaraú e Rio Turvo, Vale do Ribeira, SP. São Paulo, Convênio IPT/SICCT próminério, 4v. (Relatório IPT n² 26863)

Ferreira F.J.F., Souza J., Bongiolo A.B.S, Castro L.G., Romeiro M.A.T. 2010 Realce do gradiente horizontal total de anomalias magnéticas usando a inclinação do sinal analítico. Parte I: Aplicação a dados sintéticos. In: IV Simpósio Brasileiro de Geofísica, SBGf Brasília, Anais, p. 1-6.

Ferreira F.J.F., Souza J., Bongiolo A.B.S., Castro L.G. 2013. Enhancement of the total horizontal gradient of magnetic anomalies using the tilt angle. Geophysics, 78:J33-J41.

Fiori A.P. 1990. Tectônica e estratigrafia do Grupo Açungui a norte de Curitiba. Tese de Livre Docência, Instituto de Geociências, Universidade de São Paulo, São Paulo, 261 p.

Fiori A.P. 1992. Tectônica e estratigrafia do Grupo Açungui - PR. Boletim IG-USP, Série Científica, 23:55-74.

Heilbron M., Mohriak W., Valeriano C.M., Milani E., Almeida J.C.H. Tupinambá M. 2000. From collision to extension: the roots of the southeastern continental margin of Brazil. In: Talwani M. \& Mohriak W. (eds.) Atlantic Rifts and Continental Margins. American Geophysical Union, Washington, DC, Geophysical Monographs, p. 1-34.

Heilbron M., Pedrosa-Soares A.C., Campos Neto M., Silva L.C., Trouw R.A.J., Janasi V.C. 2004. A Província Mantiqueira: In: Mantesso-Neto V., Bartorelli A., Carneiro C.D.R. \& Brito Neves B.B. (eds.) O Desvendar de um Continente: A Moderna Geologia da América do Sul e o Legado da Obra de Fernando Flávio Marques de Almeida. São Paulo, Beca, p. 203-234.

Heilbron M., Valeriano C.M., Tassinari C.C.G., Almeida J.C.H., Tupinambá M., Siga Jr. O., Trouw R.A.J. 2008. Correlation of Neoproterozoic terranes between the Ribeira Belt, SE Brazil and its African counterpart: comparative tectonic evolution and open questions. In: Pankhurst R.J., Trow R.A.J., Brito Neves B.B, De Witt. (eds.) West Gondwana: Pre-Cenozoic Correlations across the South Atlantic Region. London, Geological Society, Special Publication, 294 p., p. 211-232.
Mantovani M.S.M., Shukowski W., Basei M.A.S., Vasconcellos A.C.B.C. 1989. Modelos gravimétricos das principais descontinuidades crustais nos terrenos pré-cambrianos dos estados do Paraná e Santa Catarina. Revista Brasileira de Geociências, 19(3):367-374.

Milani E.J. 1997. Evolução tectono-estratigráfica da Bacia do Paraná e seu relacionamento com a geodinâmica fanerozóica do Gondwana sul-ocidental. Tese de Doutorado. Porto Alegre: Instituto de Geociências, UFRGS, 255 p.

Milani E.J. \& Ramos V.A. 1998. Orogenias paleozóicas no domínio sul-ocidental do Gondwana e os ciclos de subsidência da Bacia do Paraná. Revista Brasileira de Geociências, 28(4):473-484.

Milani E.J., Melo J.H.G., Souza P.A., Fernandes L.A., França A.B. 2007. Bacia do Paraná. Boletim de Geociências da Petrobras, 15(2):265-287.

Miller H.G. \& Singh V. 1994. Potential field tilt - a new concept for location of potential field sources. Journal of Applied Geophysics, 32:213-217

Nabighian M.N. 1972. The analytic signal of two-dimensional magnetic bodies with polygonal cross-section; its properties and use for automated anomaly interpretation. Geophysics, 37:507-517.

Nabighian M.N. 1974. Additional comments on the analytic signal of two-dimensional magnetic bodies with polygonal cross-section. Geophysics, 39:85-92.

Oliveira M.J R. 1991. Análise do comportamento da zona de falha Cubatão-Lancinha na Bacia do Paraná. MS Dissertation, Departamento de Geologia, Universidade Federal de Ouro Preto, Ouro Preto, $167 \mathrm{p}$

Peternel R., Trhouw R.A.J., Schmitt R.S. 2005. Interferência entre duas faixas móveis neoproterozoicas: o caso das faixas Brasília e Ribeira no sudeste do Brasil. Revista Brasileira de Geociências, 35(3):297-310.

Portela Filho C.V. \& Ferreira F.J.F. 2003. Estimativas das taxas de extensão crustal da região central do Arco de Ponta Grossa (Bacia do Paraná) com base em modelagens aeromagnéticas. In: VIII Congresso Internacional da Sociedade Brasileira de Geofísica, SBGf Rio de Janeiro, Resumos Expandidos, CD-ROM.

Quintas M.C.L. 1995. O embasamento da Bacia do Paraná: reconstrução geofísica do seu arcabouço. Tese de Doutorado, Instituto Astronômico e Geofísico, Universidade de São Paulo, São Paulo, 213 p.

Reid A.B., Allsop J.M., Granser H., Millett A.J., Somerton I.W. 1990. Magnetic interpretation in three dimensions using Euler deconvolution. Geophysics, 55(1):80-91

Roest W.R.J., Verhoef J., Pilkington M. 1992. Magnetic interpretation using the 3-D analytic signal. Geophysics, 57:116-125.

Rosales M.J.T. 2004. Integração de dados gravimétricos terrestres e aeromagnéticos e sua aplicação ao estudo geológico-estrutural da Faixa Apiaí. Tese de Doutorado, Instituto Astronômico e Geofísico, Universidade de São Paulo, São Paulo, 271 p.

Santos Jr. G. 2005. Rede Gravimétrica: Novas perspectivas de ajustamento, análise de qualidade e integração de dados gravimétricos. Tese de Doutorado, Departamento de Ciências Geodésicas, Universidade Federal do Paraná, Curitiba, 165 p.

Siga Jr. O., Basei M.A.S., Reis Neto J.M., Machiavelli A., Harara O.M.M. 1995. O Complexo Atuba: um Cinturão Paleoproterozóico intensamente retrabalhado no Neoproterozoico. Geologia USP: Série Científica, São Paulo, 26:69-98.

Siga Jr. O. 2010. Geocronologia da porção sul do Terreno Apiaí: implicações tectônicas. Tese de Livre- Docência. Instituto de Geociências, Universidade de São Paulo, São Paulo, 89 
Soares P.C, Barcellos P.E, Csordas S.M., Mattos J.T., Balliero M.G., Meneses P.R. 1982. Lineamentos em Imagens Landsat e Radar e suas implicações no conhecimento tectônico da Bacia do Paraná. In: II Simpósio Brasileiro de Sensoriamento remote, CNPq/INPE. Brasília: v.1 43-56

Talwani M. \& Heirtzler J.R. 1964. Computation of gravity anomalies caused by two dimensional structures of arbitrary shapes. Geologic Sciences. 1(9): 464-480.

Talwani M., Worzel J.L., Landisman M. 1959. Rapid gravity computations for two dimension bodies with the application to the Mendocino submarine fracture zone. Journal of Geophysics Research, 69:49-69.

Telford W.M., Geldart L.P., Sheriff R.E. 1990. Applied Geophysics. Cambridge, Cambridge University Press, 770 p.

Thompson D.T. 1982. EULDPH: A new technique for making computerassisted depth estimates from magnetic data. Geophysics, 47:31-37.
Verduzco B., Fairhead J.D., Green C.M. 2004. New insights into magnetic derivatives for structural mapping. The Leading Edge, 23(2):116-119

Wijins C., Perez C., Kowalczyk P. 2005.Theta map: Edge detection in magnetic data. Geophysics, 70:L39-L43.

Won I.J. \& Beavis M. 1987.Computing the Gravitational and Magnetics anomalies due to a polygon: Algorithms and Fortran subroutines. Geophysics, 52:232-238.

Zalán P.V., Wolff S., Conceição J.C.J., Vieira I.S., APPI V.T., Zanotto O.A. 1987. Tectônica e Sedimentação da Bacia do Paraná. In: Simpósio Sulbrasileiro de Geologia, SBG Curitiba, Atas, p. $441-474$

Arquivo digital disponível on-line no site www.sbgeo.org.br 